\title{
Methodology for design decision support of cost-optimal zero-energy lightweight construction
}

\author{
Mohamed Amer ${ }^{\mathrm{a}}$, Mohamed Hamdy ${ }^{\mathrm{b}}$, Thomas Wortmann ${ }^{\mathrm{c}}$, Ahmed Mustafa ${ }^{\mathrm{d}}$, Shady Attia ${ }^{\mathrm{a}, *}$ \\ ${ }^{a}$ Sustainable Building Design Lab, Dept. UEE, Faculty of Applied Sciences, Université de Liège, Belgium \\ ${ }^{\mathrm{b}}$ Department of Civil and Environmental Engineering, Norwegian University of Science and Technology, Norway \\ ' Xi'an Jiaotong Liverpool University, China \\ ${ }^{\mathrm{d}}$ Urban Systems Lab, The New School University, USA
}

\section{A R T I C L E I N F O}

\section{Article history:}

Received 30 March 2020

Revised 4 May 2020

Accepted 19 May 2020

Available online 22 May 2020

\section{Keywords:}

Multi-objective optimization

Building performance

Simulation

Solution space

Urban densification

Roof stacking

\begin{abstract}
A B S T R A C T
The interest to find cost-optimal zero-energy solutions for building, using multi-objective optimization, has risen dramatically over the last decade. Accordingly, several studies have been carried out, proposing new methods and tools. None, however, has introduced a simplified approach that is viable by a broader range of users. This study addresses this lack, offering a methodology that supports the decision making process on cost-optimal zero energy building, using a novel approach, namely Multi-Objective Parametric Analysis (MOPA), rather than optimization algorithms. This study adds to the domain of roof stacking construction by setting the weight of construction as a third objective. The current methodology is applied to a newly developed theoretical Reference Building (RB) for a Belgian passive roof stacking house. Different options of the building's superstructure components (walls, roof, and windows) have been examined. MOPA follows three consecutive steps: modeling setup, parametric simulation, and ends up with evaluation and selection. The results show cost-optimal zero-energy and lightweight packages of design variables for the building envelope.
\end{abstract}

(ㄷ) 2020 Elsevier B.V. All rights reserved.

\section{Introduction}

\subsection{Background}

According to the latest studies by the International Energy Agency, IEA [1], it was found that the building sector accounts for $36 \%$ of carbon emissions, $40 \%$ of the energy demand in the European Union. The need for housing and construction is increasing due to the exponential increase in the world's population, which is estimated to increase by $32 \%$ in 2050 [2]. Nevertheless, the increasing need for housing is evident in major cities due to the polarization of intellectuals and highly skilled laborers seeking better job opportunities and higher salaries [3]. Accordingly, new urban agendas manifestly address this subject in response to the need for new housing construction while limiting urban sprawl on the outskirts of the cities [4]. Roof stacking has been put forward by several researchers and practitioners as a solution to accommodate the increasing population while conserving the urban landscape and ecology [5-9]. As shown in Fig. 1, Roof stacking is defined as the added structure over the rooftop of an existing

\footnotetext{
* Corresponding author.

E-mail address: shady.attia@uliege.be (S. Attia).
}

building to create one or more stories of living spaces [7]. Moreover, several international and European calls have emerged to apply stricter regulations on the building industry to achieve net zero-energy buildings (nZEBs) by 2020, and reduce the overall carbon emission of the buildings [10-13]. However, cost-optimality of buildings should be considered when opting for high energy performance buildings. Thus, to achieve cost-optimal and energy efficient buildings, the Energy Performance in Buildings Directive EBPD-recast in 2010 [14] requests the EU Member States to ensure achieving cost-efficient optimal level when designing for minimum energy use for buildings. The same request goes for nZEBs, which should be feasible for implementation. The fact is, achieving this target is a difficult task, as it requires exploring a huge number of design solutions resulting from exploring a different number of design variables. Therefore, and in alignment with EPBD requirements, it has been of great interest from the scientific community and industry to study and promote cost-optimal and energy efficient buildings.

\subsection{Previous work}

The EPBD recast 2010 came in force ten years ago. A revised EPBD came into force in 2018 to include smart readiness in build- 

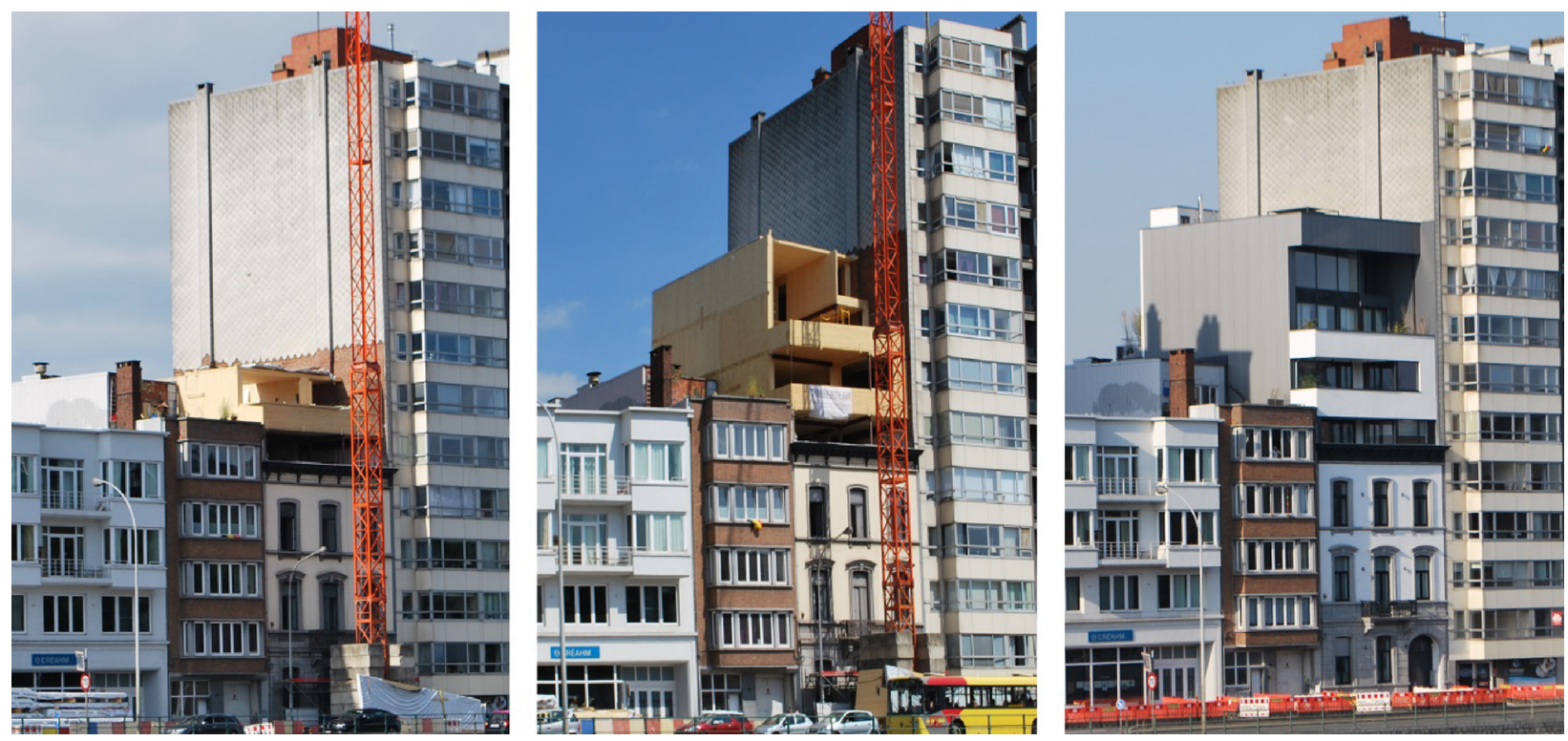

Fig. 1. An example of a roof stacking over an existing rooftop.

ings [15]. Since then, several studies have investigated both the economic and environmental aspects of the buildings. For instance, Hamdy et al. [16] introduced an efficient and time-saving simulation-based optimization method to find cost-optimal and nZEB energy performance levels. The method is based on the exploration of several parameters for building envelops and HVAC systems throughout three consecutive steps. Mauro et al. [17] developed a new methodology to provide robust solutions for cost-optimal energy retrofitting measures for several building categories. The methodology was based on simulation-based uncertainty analysis, followed by a sensitivity analysis that identifies optimum retrofitting solutions. Several retrofit packages, which include energy saving measures, energy efficient HVAC systems, and renewables, are investigated by means of cost-effectiveness. Hamdy and Siren [18] have further investigated the topic, where a new multi-aid optimization scheme has been developed to support the decision-making on robust cost-optimal decisions on multiple energy performance levels of buildings. This new scheme aimed to minimize the computational effort done to explore, possibly, an enormous number of design and operation design options. Another method that visually supports the decision-making process on the most beneficial economic design solutions has been developed [19]. This method was established on a novel optimization-based parametric analysis scheme to investigate a large number of economic scenarios in a relatively short time. Moreover, several multi-objective evolutionary algorithms of optimization, which are widely used, have been examined through a comparative analysis [20].

Further research has been carried out to answer the question of how to obtain the most cost-efficient design packages that reduce energy use. Ascione et al. [21] answered this question by developing a new methodology that utilizes multi-objective optimization of building's energy performance while maximizing indoor thermal comfort. The same approach has been used to assess costoptimal solutions for energy retrofitting of hospitals [22], where multi-stage and multi-objective optimization has been used aiming to reduce the computational burden required to achieve robust retrofit solutions. Furthermore, the multi-objective optimization method is developed to include costs, incentives, indoor comfort, energy demands for heating and cooling in the simulation and optimization process. The developed method aimed to propose a wide choice of best configuration options to retrofit education buildings [23]. Ascione et al. [24] have further developed his methods by employing artificial neural network by coupling EnergyPlus and MATLAB. By using genetic algorithms, it is possible to minimize energy use and thermal discomfort and define the "most" cost-optimal design packages. A similar framework has been proposed to ensure a robust assessment of cost-optimality while combating global warming and provide the highest resilience to the cited scenarios. Thus, by encouraging building more costeffective and highly energy efficient buildings, it is possible to provide a safe way towards fighting climate change [25].

Other researchers have investigated the same topic, though, more explicitly by studying specific building components or systems to find optimum solutions, which illustrates the Pareto tradeoff curve between energy and cost. For instance, Georges et al. [26] carried out examinations on building systems in single-family houses to find the optimum combination of heating systems and building construction. Marszal and Heiselberg [27] aimed to find optimum results by investigating the effect of three different energy demand and supply systems on the life cycle cost for netzero energy residential houses. Cristina et al. [28] studied the effect of different climate zones on the multi-objective optimization results when aiming to reduce the energy requirements for heating, cooling, and domestic hot water production. While others attempted to propose a multi-objective optimization design tool based on automated optimization methods using NSGAII algorithm [29-31].

Although the scientific community has proposed a numerous of multi-objective optimization methods, there are a limited number of studies that consider the implications of roof stacking on the reduction of carbon emissions and energy use of existing buildings [6-8,32-36]. Generally, it is argued that by providing more compact cities, it is possible to reduce the energy use on the building and transportation scale [37-39]. For instance, Marique and Reiter [40] found that by increasing the neighborhood densities alone without applying retrofitting measures, it is possible to reduce up to $30 \%$ of the total energy use. Since the characteristics of the building envelope highly affect the overall energy performance of residential buildings in all scales, achieving zero-energy buildings requires using thick walls and insulations, which is accompanied in most cases with additional weight in construction [41]. This 
represents a conflict in the design objectives when opting for lightweight construction. Amer et al. [42] have proposed a framework to achieve cost-optimal zero-energy and lightweight construction, as a mean of tackling multi-objective design targets. The choice of lightweight construction has been put forward as an objective based on a wide survey conducted among building engineers who have expertise in building on rooftops around Europe. The results of this survey show that the weight of the construction is an essential criterion when choosing the optimum combination of building parameters [32].

\subsection{Aim and contribution of this study}

As shown in the previous studies, to achieve multi-objective design solutions, complex methods and tools for analysis and optimization have been introduced, which is far beyond the capacity of architects, building engineers, and decision-makers to implement in reality [43]. The methods employed are sophisticated and use intertwined computational approaches by integrating several platforms, such as MATLAB, EnergyPlus, artificial neural network, and other optimization algorithms. Using such methods is not practically feasible, especially for small and mid-size projects [44]. Besides, there is a huge paradox when choosing the right optimization algorithm. Even though GA is mostly used in building performance optimization [20], it has been proven that it is not the most efficient algorithm to solve building energy simulation problems, not to mention the multi-objectivity of the design problem [45]. Unless the optimization process is performed by an expert in the field of optimization, it is hard to choose or use the right algorithm.

Therefore, this study aims to introduce a simplified methodology, which provides a concrete approach to achieve multipleobjective design targets, which allows assessing the influence of different building parameters on each of the energy use, global cost, and later the overall added weight of construction. The methodology aligns with the common practices in the design process, while facilitating the complexity of the decision-making in early design phases, providing robust and reliable results for the development of the design. The originality of this research work lies within the following objectives:

1. Introducing a simplified method, in terms of complexity of the calculation process and required tools for investigation and identification of optimum design packages. This process is based on parametric analysis rather than using optimization algorithms.

2. Integrating the weight of construction as an objective in the optimization process, which is therefore concerned with roof stacking type of buildings?

3. Defining a Reference Building concerning roof stacking type of construction.

The methodology of this research, attempt to reduce the required labor-intensive and time-consuming simulations methods in order to achieve multi-objective design targets for small and mid-size projects, more specifically for residential buildings with discrete variables of building components. The methodology avoids using sophisticated mathematical approaches, such as uncertainty and sensitivity analysis, not to mention the paradox of choosing the right optimization algorithms.

The methodology consists of a multi-stage decision-making framework, based on parametric analysis. Each step provides an informative milestone in the decision-making process. Furthermore, in order to validate the methodology and realize the third objective, the developed methodology has been applied to a theoretical Reference Building, which has been developed in this research. The RB is based on passive house standards and the representative middle-class housing typology of the existing building in Brussels, the capital of Belgium and the European Union. The developed methodology is denoted as "Multi-Objective Parametric Analysis" (MOPA). This methodology can be applied to individual buildings, as well as a building stock that holds the same characteristics. Thus, the decision-making process could be used on a broader scale.

This study is composed of eight sections. An introduction to this research is presented in the first section, where a thorough review of literature, in the last decade from 2009 till 2019, has been carried out. The study presented the previous efforts in developing methods for multi-objective optimization for energy and cost in alignment with EPBD recommendations, shedding light upon the topic of roof stacking as a requirement that is needed to study within the same research context. The second section thoroughly introduces and illustrates the developed methodology. A reference building has been developed in the third section of this paper, on which the methodology has been applied. The objectives and design variables of the case study have been set in the fourth section. In the fifth section, the novel approach of this research is presented, where the steps of the multi-objective parametric analysis (MOPA) is being applied in the case study. The post-processing phase is introduced in the sixth section, where optimum design variables are identified and selected. The seventh section provides a summary of the main findings and highlights the strengths and limitations, while draws recommendations for further research. The eight and last section concludes the outcomes of this research.

\section{Methodology}

Building geometry and parametric variations have been designed by Grasshopper graphical algorithm editor, a built-in plugin in Rhinoceros 3D modeling tool, which is widely used by architectural engineers and is interoperable with BIM tools. Ladybug and Honeybee plugins, which are integrated into Grasshopper, have been used as Building Performance Simulation (BPS) tools and Building Performance Optimization (BPO) tools [46]. Ladybug and Honeybee plugins work as an interface to OpenStudio and EnergyPlus, which is used to run annual dynamic energy simulations with high accuracy and reliability for multi-zone and complex buildings [47].

For cost and building's weight analysis, mathematical calculations have been designed and employed in the same Grasshopper "Canvas" or interface, together with energy simulation plugins. Thus, by using the Grasshopper parametric tool, a multi-objective parametric analysis is conducted using the same Graphical User Interface GUI. Finally, Microsoft Excel has been used as a complementary tool for storing and post-processing results.

The methodology is composed of three main stages, Fig. 2. Each stage is composed of several steps, as explained in detail in the following sections. Those stages are summarized below:

- Stage One: In practice, this step simply identifies the boundary conditions of a project. In this research, the base case reference building is being defined, where multi-objective design targets and design variables are being set for analysis.

- Stage Two: Parametric analysis is taking place in this stage, where design variables are being analyzed in a simultaneous and multistep procedure. Throughout this stage, optimum design variables are being identified. Cross influencing has been done in the first stage based on selected solutions from the Pareto Front. The relation was inversely proportional. Then, in stage 2, we cross influencing the optimal results again based on the new Pareto front. 


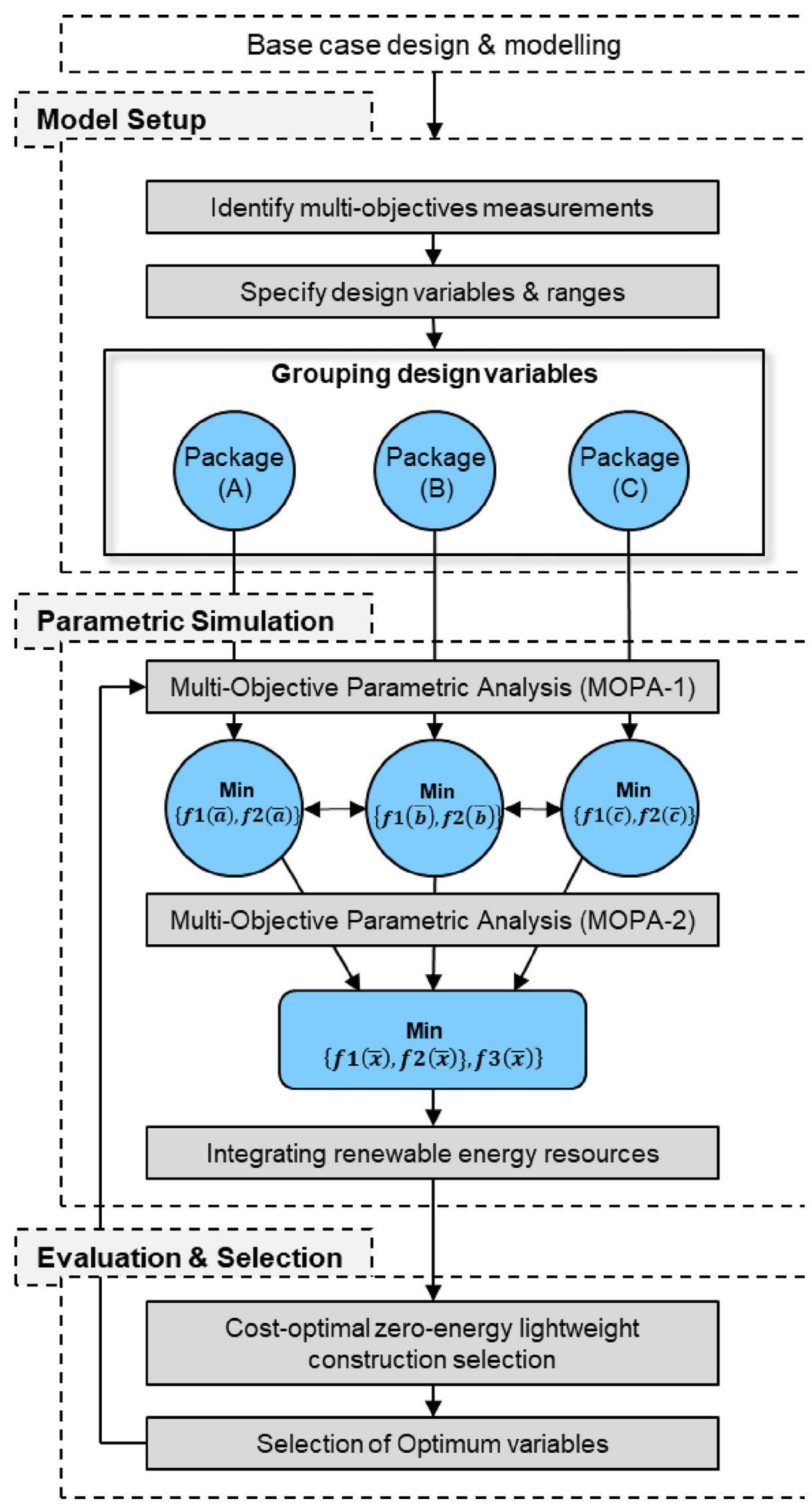

Fig. 2. Methodology framework for multi-objective design variables selection for cost-optimal zero-energy lightweight construction. 
- Stage Three: Decision-making process on the optimum variables that achieve multi-objective design targets takes place in this stage. This process takes carried out by illustrating 3D charts and parallel coordinated graphs, which play an essential role to understand better and visualize the results.

It needs to be claimed that the objective functions are monotonic to the variables. There exists at least one active constraint which bounds the variable in the direction opposite to the objective. A constraint is considered active if it acts at its lower or upper bound.

\section{Case study}

Since EPBD is concerned with the Member States of the European Union (EU) [14,15], Brussels Capital Region in Belgium, as the capital of Europe, has been chosen for the location of the case study. However, there is a lack of any benchmark or a reference that represents the performance of roof stacking buildings in Brussels. Therefore, a Reference Building (RB) has been developed in this research. Based on the available data, there are three different models to identify a RB: Real, example, and theoretical $[48,49]$.

Real RB simply represents an existing building for a certain typology, where the characteristics of the building are identified, and performance is measured based on monitored data. Example $\mathrm{RB}$ represents an ideal building defined based on the inquiries and assumptions of experts, whereas theoretical RB is identified based on statistical data (i.e., the one here adopted in this research). A theoretical RB has been developed on two bases: the first base is the Belgian passive house standard, and the second base is buildings' configuration of existing typologies, given that the RB has to be built on the rooftop of an existing building. Thus, we opt to follow the Belgian passive house standards to develop a RB. However, we found no roof stacking buildings that comply with passive house standards. Accordingly, a reference model of a passive house has been selected. The selection of the passive house reference model has been based on several criteria, such as construction material, climatic zone, layout, and available data.

The second step is based on previous studies that classified existing housing typologies in the Brussels Capital Region, where the most representative housing typology has been selected [50]. Based on the statistical data that has been previously mentioned, in addition to the previous research on roof stacking, a theoretical RB has been developed, and boundary conditions have been set. Building parameters and variables have been precisely identified according to the available building materials and components in the Belgian market in order to represent a real project condition. This section demonstrates a novel approach to develop and characterize a RB for roof stacking buildings.

\subsection{Reference building $(R B)$ development}

Since this research is concerned with roof stacking in the European context, the Brussels Capital Region was chosen for the location of the case study, as the capital of Belgium and the EU. Moreover, Brussels has the fastest growing population among other Belgian cities, expecting 190,000 more inhabitants by 2040 $[51,52]$. Thus, urban densification through roof stacking has been put forward as a prospect solution [6,8]. However, in Brussels, there are several building typologies that differ in layouts and composition. In order to narrow down the selection, building typologies have been identified based on the review of the literature. Firstly, there is a distinct difference between residential buildings that were built before 1945 and after, which marks the end of the Second World War and the beginning of a new era of industri- alization in the field of construction. The majority of the existing buildings are those that were built before 1945, representing $71 \%$ of the existing residential building in Brussels, which had similar characteristics in terms of building's scale, height, and typologies [50]. Among those buildings, middle-class housing typology represents the most common typology, which represents $78 \%$ of the total residential buildings that were built before 1945 .

The characteristics of the building envelope and system of the $\mathrm{RB}$ in this research has been identified based on a reference building for a cluster composed of 22 row passive houses in Hannover in Germany, which was found to be similar to the layout of the reference passive house that has been selected in this study as shown in Fig. 2. A typical layout for a ground floor of a middle-class house is composed of living and dining rooms and stairs that connect to the upper floor, which is usually composed of bedrooms and bathrooms.

In fact, it is important to clarify that passive house standards slightly differ from one country to another. For instance, in German standards, the indoor air temperature higher than $25^{\circ} \mathrm{C}$ should not exceed $10 \%$ of the occupancy hours, whereas in the Belgian standards, indoor air temperature of $25{ }^{\circ} \mathrm{C}$ should not exceed $5 \%$ of the occupancy hours. In this research, the RB has been developed based on the German reference passive house while complying with Belgian passive house standards taking into consideration the differences in the required performance (e.g., overheating hours). A full document has been published to identify the characteristics and performance of passive house buildings based on monitored values [53], which has been used to simulate and calibrate the model.

The selection of the reference passive house has been based on five fundamental characteristics. Those fundamentals match the characteristics of the roof stacking model in Brussels, which are described as follows:

- Climate zone, where both houses lie in the same climatic zone according to Koppen climate classification, where Typical Metrological Year (TMY) weather files have been used in simulations.

- Function, where both buildings have the same residential function.

- Layout, as will be explained in detail in the next section, the reference house has the same dimensions in terms of length, width, height, in addition to the same layout composition.

- Building materials are cross-laminated timber, which is used as a lightweight material [32].

- Data availability, where specifications of building materials, mechanical systems and monitored data for energy use and indoor temperatures are found in the full report [53], which is necessary for calibration.

More importantly, there are general requirements for passive house standards, which include some thresholds for building performance, and others related to the building physics. The passive house standard requirements related to building performance are the heating demand, which should not exceed $15 \mathrm{kWh} / \mathrm{m}^{2} / \mathrm{yr}$., and total energy use, which should not exceed $45 \mathrm{kWh} / \mathrm{m}^{2} / \mathrm{yr}$. In addition, achieving thermal comfort that should be met in all living spaces that should not exceed $5 \%$ of occupancy hours with indoor air temperature more than $25{ }^{\circ} \mathrm{C}$. While the characteristics that are related to building physics are the thermal performance of the wall section that should not exceed a U-value of $0.15 \mathrm{~W} / \mathrm{m}^{2} . \mathrm{K}$, roof section that should not exceed a U-value of $0.10 \mathrm{~W} / \mathrm{m}^{2} . \mathrm{K}$, and window with a maximum U-value $0.85 \mathrm{~W} / \mathrm{m}^{2} . \mathrm{K}$. Moreover, the building should be airtight with no more than 0.6 air changes per hour at 50 Pascal pressure. 


\subsection{Model characteristics}

The RB has been developed and identified under two main sets: (a) Geometry and Function according to the Belgian housing typology, and (b) envelope and system according to the passive house reference building.

\subsubsection{Geometry and function}

The geometry is similar to the household presented in Fig. 1 and has been simplified into three zones building [16], composed of two bedrooms zones and one zone for stairs and bathroom on the top floor, as shown in Fig. 3. The building is similar to a row house with two side walls next to two neighboring buildings, facing the north-south direction. The added floor follows the same layout of the floor below with a shorter length of $9 \mathrm{~m}$ length and $6 \mathrm{~m}$ in width. The first and second zones have areas of $22 \mathrm{~m}^{2}$ and $14 \mathrm{~m}^{2}$, while the last zone has an area of $8 \mathrm{~m}^{2}$, to make the whole floor with an area of $44 \mathrm{~m}^{2}$. However, the Treated Floor Area (TFA), on which the passive house standard counts, is calculated for the two bedrooms that make an area of $36 \mathrm{~m}^{2}$.

\subsubsection{Envelope and system}

As shown in the previously, building geometry has been developed based on the existing layout of the housing typology, whilst the characteristics and composition of the building envelope have been developed based on the passive house reference building, with a direct reference with the existing building materials in the Belgian market. The thermal characteristics of the building materials, namely the thermal conductivity, specific heat capacity, and density are defined based on the standard EN ISO 10456 [55]. The cost of the building materials, which is used to define the Life Cycle Cost (LCC) of the RB, has been determined based on the database of the Belgian construction works for 2017 entitled "Bordereau des Prix Unitaires".

The characteristics of the building envelope are shown in Table 1 as prescribed in the reference passive house [53]. The walls facing
Table 1

Building envelope's characteristics of the reference passive house.

\begin{tabular}{ll}
\hline Building Physics & $\mathrm{U}-$ Value $\left(\mathrm{W} / \mathrm{m}^{2} . \mathrm{K}\right)$ \\
\hline Wall & 0.126 \\
Roof & 0.095 \\
Floor & 0.125 \\
Window $\left(\mathrm{U}_{\mathrm{w}}\right)$ & 0.83 \\
Triple glazing (g-value 0.6$)\left(\mathrm{U}_{\mathrm{g}}\right)$ & 0.75 \\
Aluminum frame $\left(\mathrm{U}_{\mathrm{f}}\right)$ & 0.57 \\
\hline
\end{tabular}

the north and south directions are made of lightweight timber frames, and $300 \mathrm{~mm}$ mineral wool insulation, with a U-value of $0.126 \mathrm{~W} / \mathrm{m} 2 . \mathrm{K}$. The roof section is made as well of lightweight timer frames but with $400 \mathrm{~mm}$ mineral wool insulation to have a U-value of $0.095 \mathrm{~W} / \mathrm{m}^{2} . \mathrm{K}$. The north façade that occupies the Bedroom has a Window to Wall Ratio (WWR) of $20 \%$, while the south façade, which occupies the living room, has a WWR of 30\%. Both windows are made of low-emissive triple-glazing, with a U-value of $0.75 \mathrm{~W} / \mathrm{m}^{2} . \mathrm{K}$, g-value $60 \%$, and a frame U-value of $0.57 \mathrm{~W} / \mathrm{m}^{2}$. $\mathrm{K}$, with an average effective window $\mathrm{U}$-value of $0.83 \mathrm{~W} / \mathrm{m}^{2} . \mathrm{K}$ to comply with passive house standards. The windows are designed to prevent thermal bridges. The U-values of the sidewalls and floor are equal to $0.097 \mathrm{~W} / \mathrm{m}^{2} . \mathrm{K}$ and $0.125 \mathrm{~W} / \mathrm{m}^{2} . \mathrm{K}$, respectively. However, the precise composition of both elements has not been taken into consideration since they are designed in concrete. Instead, wall and floor sections with equivalent thermal transmittance values (U-values) have been substituted to maintain an overall lightweight construction.

According to the passive house reference building, the house is connected to an integrated district heating transfer station and decentralized post-heater elements located in each building's services floor, which cannot be applied for the existing buildings in Brussels. Instead, a Heat Pump has been assigned for the developed $\mathrm{RB}$, which is responsible for heating and cooling, with a Coefficient of Performance (COP) of 4 . To achieve indoor thermal comfort, setpoint temperatures for heating and cooling have been identified
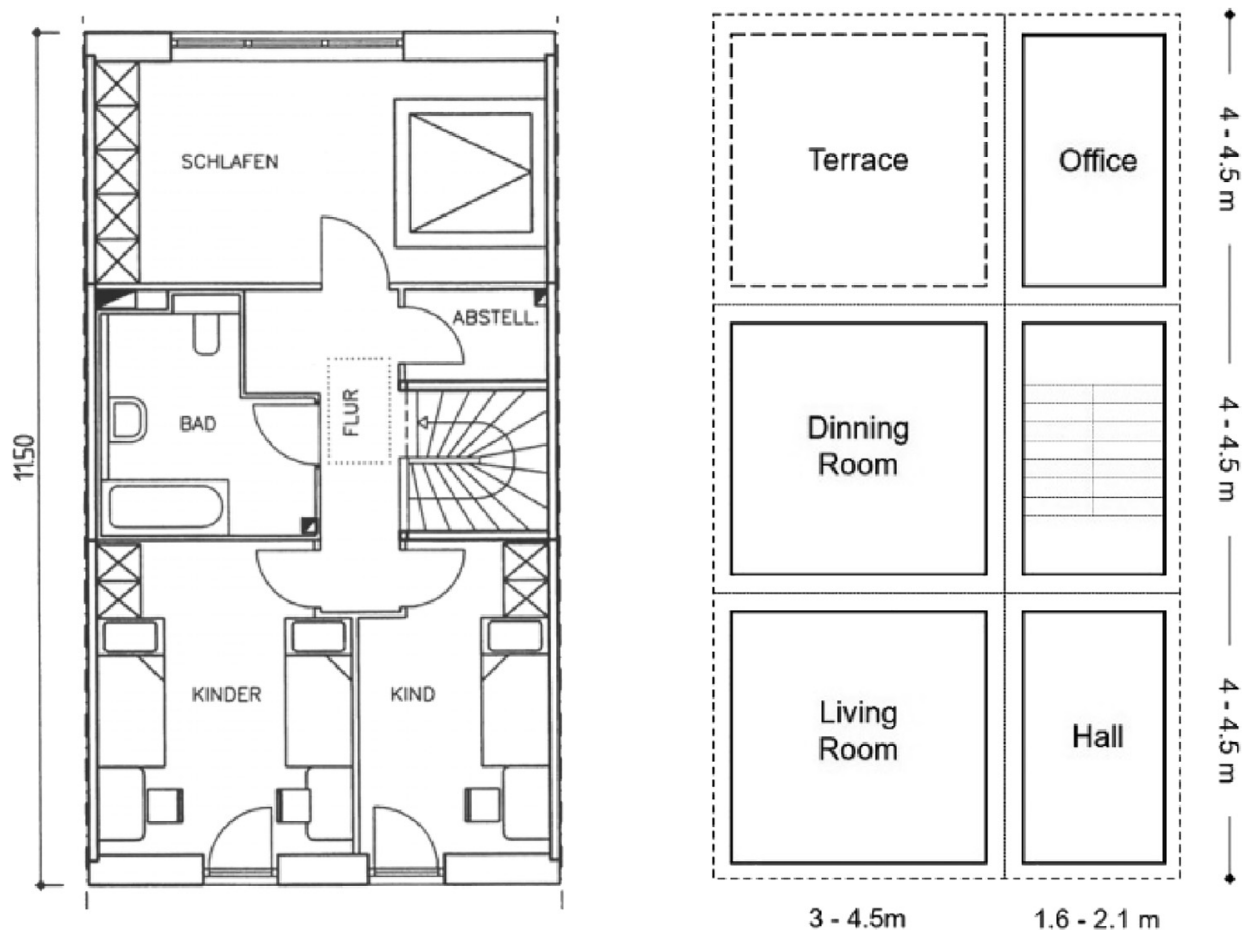

Fig. 3. On the left is the layout of the reference passive house. On the right is the typical layout of the middle-class housing typology in Brussels [53,54]. 
based on ASHRAE standard 55-2004 for adaptive comfort model and the recommended indoor temperatures as defined in the reference passive house, with a $20^{\circ} \mathrm{C}$ for heating setpoint and $26{ }^{\circ} \mathrm{C}$ for cooling set point. In this model, indoor air temperatures should not exceed the $25^{\circ} \mathrm{C}$ for $5 \%$ of the occupied hours to comply with the Belgian passive house standards. As for the ventilation, a mechanical system with heat recovery has been added, namely system D. The efficiency of the heat recovery system is designed at $80 \%$, with a constant airflow of $30 \mathrm{~m}^{3} / \mathrm{h}$ for each room. Regarding the consumption of the Domestic Hot Water (DHW), it has not been considered in the calculations since DHW is provided by the district heating system and supported by solar heaters in the reference passive house, which is not applicable in the case study in Brussels. Thus, given the nature of roof stacking buildings, DHW is assumed to be previously provided in the existing building. Moreover, according to previous studies [16], it was found that solar heaters have lower economic availability compared to the PV system. Solar heaters were found to increase the investment cost and the replacement cost since it has a shorter life-space than the PV system. Whereas the electricity consumed by house appliances and lighting has been designed with a constant value of $19.8 \mathrm{kWh} /$ $\mathrm{m}^{2}$, to match the passive house reference building, which means that lighting consumption has not been designed based on the indoor daylighting availability. Table 2 illustrates in detail the specifications of the mechanical system and the energy used for heating and auxiliary electricity. The reference passive house has been designed with the active cooling system (based on the reversible heap pump), given that indoor temperatures, maximum variation ranges between $22.3{ }^{\circ} \mathrm{C}$ and $26.4{ }^{\circ} \mathrm{C}$ throughout the whole year, thanks to the mechanical ventilation system. Thus, the active cooling system was not used.

\subsection{Simulation and calibration}

As shown in the previous section, the parameters of the RB have been set based on two different sets of information: (a) Geometry and function, (b) Envelope and system. Several adjustments have been made from each set to match the specific characteristics of a roof stacking building.

The RB has been simulated and calibrated based on the monitored values of the passive house reference building. The calibration has been made based on the monthly monitored values of the heating energy demand and average indoor temperature as shown in Fig. 4.Indoor air temperature, and relative humidity were monitored simultaneously in one bedroom and the living room. The temperature and humidity were monitored using a HOBO U12-012 data logger. This was a four-channel data logger with 12-bit resolution. The monitoring was done between 2016 and 2019.

In order to calibrate the RB simulation model, the settings of the defined model characteristics have been set as constants, while variations on the occupancy schedules and the U-value of the neighboring side walls have been applied, as shown in Table 3.

Table 2

Mechanical system's characteristics of the reference passive house.

\begin{tabular}{ll}
\hline Mechanical System & Value \\
\hline Heating demand & $14.9 \mathrm{kWh} / \mathrm{m}^{2} . \mathrm{a}$ \\
House appliances and lighting & $19.8 \mathrm{kWh} /\left(\mathrm{m}^{2} \mathrm{a}\right)$ \\
Auxiliary electricity (heat recovery) & $2.2 \mathrm{kWh} /\left(\mathrm{m}^{2} \mathrm{a}\right)$ \\
Auxiliary electricity (heating fan) & $1.4 \mathrm{kWh} /\left(\mathrm{m}^{2} \mathrm{a}\right)$ \\
Heat recovery effectiveness & $80 \%$ \\
air volume flow & $120 \mathrm{~m}^{3} / \mathrm{h}$ \\
Ventilation airflow (Living room) & $30 \mathrm{~m}^{3} / \mathrm{h}$ \\
Ventilation airflow (Bedroom) & $30 \mathrm{~m}^{3} / \mathrm{h}$ \\
Air tightness & $0.29 \mathrm{~h}^{-1}$. \\
\hline
\end{tabular}

The variation of the occupancy schedule has been set within a margin of $\pm 4 \mathrm{~h}$. While, $\mathrm{U}$-value of the neighboring sidewalls are set to vary between 0.2 and $0.8 \mathrm{~W} / \mathrm{m}^{2} \mathrm{~K}$, with a $0.05 \mathrm{~W} / \mathrm{m}^{2} \mathrm{~K}$ uniform step. A total of 1024 options could be achieved when cross-referencing the operational, occupancy schedule parameters, and neighboring sidewalls. Thus, Genetic Algorithms (GA) have been used to run an automated calibration, which brings optimized fitness values after 270 simulations run only. The tools that have been used for calibration are the same used in the parametric simulation and data analysis. More information and details are explained in the next sections.

Two indices have been used to verify the good-to-fit of the building energy and thermal model [56-58]. The first index is the Mean Bias Error (MBE), as shown in the first equation, and the Coefficient of Variation of the Root Mean Square Error (CV (RMSE)) as shown in the second equation.

$\mathrm{MBE}=\sum_{i=1}^{N p}\left(m_{i}-s_{i}\right) / \sum_{i=1}^{N p} m_{i}[\%]$
$\mathrm{CV}(\mathrm{RMSE})=\sqrt{\sum_{i=1}^{N p}\left(m_{i}-s_{i}\right)^{2} / N p[\%]}$

where the $m_{i}:(\mathrm{i}=1,2,3 \ldots, \mathrm{Np})$ represents the monitored data points, while $s_{i}$ : $(\mathrm{i}=1,2, \ldots, \mathrm{Np})$ represents the simulated data points. MBE represents a non-dimensional measure of the bias error between the simulated and measured data in a specific time resolution. RMSD represents the standard deviation of the differences between the simulated and measured data, which aggregates the magnitudes of the errors for various times into a single measure. Both indices are expressed in percentages. Based on the guidelines of ASHRAE 14-2002 and 2014, the maximum threshold for MBE is $5 \%$ for monthly calibrated data points and $10 \%$ for hourly calibrated data points. CV (RMSE) requires a maximum limit of $15 \%$ for monthly calibrated data points and $30 \%$ for hourly calibrated data points. Fig. 4 represent the calibration results of the monthly heating demand, where the values of MBE and CV (RMSE) are equal to $2.1 \%$ and $7.3 \%$, respectively. While the values of the monthly average indoor temperature are equal to $1.3 \%$ and $4.7 \%$, respectively. The increase in the monitored value in July is mainly due to the heatwave of the year 2019. The calibration values for both the heating demand and indoor temperatures ensure the reliability of the simulation model to be used in further analysis.

\section{Model setup}

In the course of achieving multi-objective optimal solution space, the process is divided into several steps or groups. Each group represents a milestone in the decision-making process. In this study, a parametric analysis is run over three groups: wall, roof, and windows. Afterward, the renewable energy group is added in order to achieve zero-energy solution space. Out of the parametric analysis of each group, multi-objective optimum results are selected through the Pareto front, where optimum design variables are identified accordingly. Afterward, those optimum variables are selected for secondary parametric analysis to obtain optimum measures for the whole building. By using such a method, we tend to avoid the complexity of choosing and using optimization algorithms while getting multi-objective optimum results.

\subsection{Design objectives}

The aim of the proposed methodology is to find the minimum value of three objective functions: $\operatorname{Min}\{f 1(\bar{x}), f 2(\bar{x}), f 3(\bar{x})\}$

Where $f 1$ represents the energy use, $f 2$ represents the difference in life-cycle cost between the RB and any design option, and 

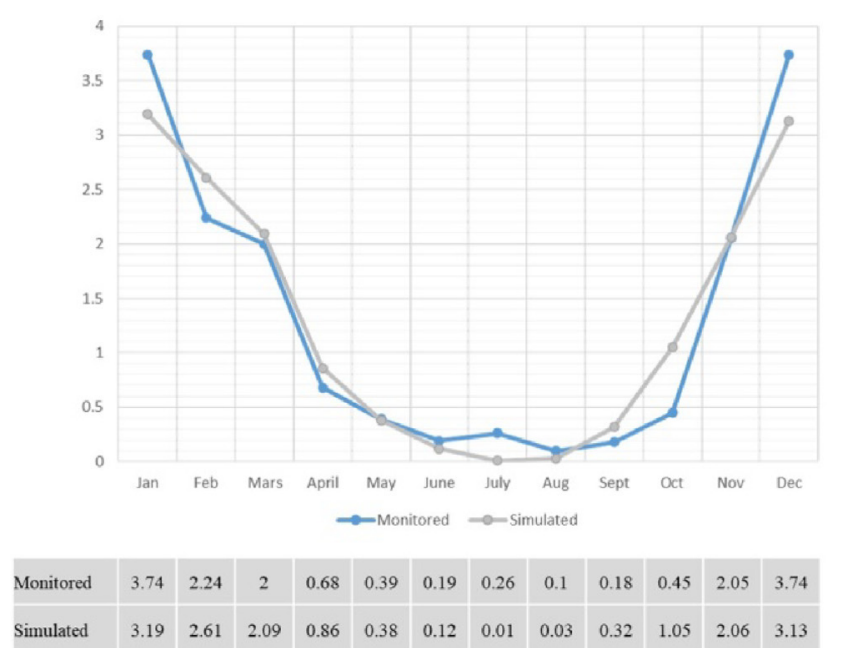

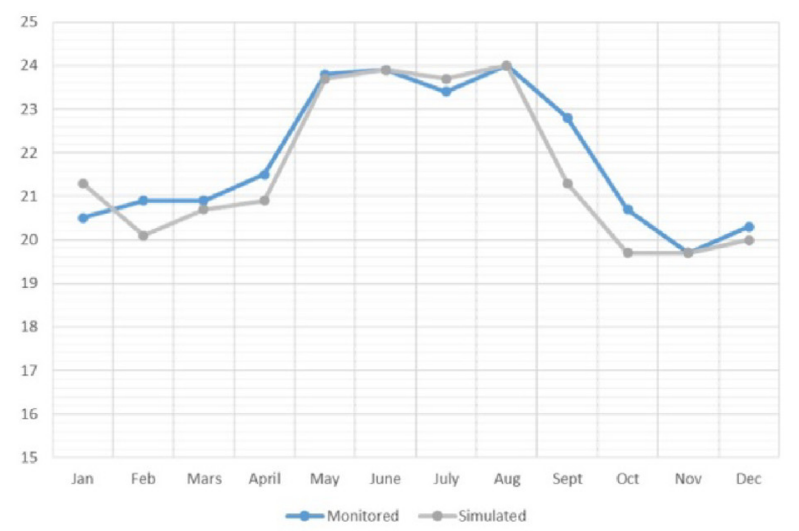

\begin{tabular}{l|l|l|l|l|l|l|l|l|l|l|l|l|} 
Monitored & 20.5 & 20.9 & 20.9 & 21.5 & 23.8 & 23.9 & 23.2 & 24 & 22.8 & 20.7 & 19.7 & 20.3 \\
\hline
\end{tabular}

\begin{tabular}{l|l|l|l|l|l|l|l|l|l|l|l|l|} 
Simulated & 21.3 & 20.1 & 20.7 & 20.9 & 23.7 & 23.9 & 23.7 & 24 & 21.3 & 19.7 & 19.7 & 20 \\
\hline
\end{tabular}

Fig. 4. a, Calibration values for heating energy demand in $\mathrm{kWh} / \mathrm{month}$; $4 \mathrm{~b}$ Calibration values for indoor air temperature in Celsius.

Table 3

Reference Building (RB) Wall and roof section composition.

\begin{tabular}{llll}
\hline Wall & Cost $/ \mathrm{m}^{2}$ & Weight $/ \mathrm{m}^{2}$ & Area \\
\hline Larch (Cladding) & 25.00 & 14.4 & 74.55 \\
Gypsum (Plaster Board) & 45.00 & 11.5 & \\
OSB (Particle Board) & 30.00 & 6.2 & \\
MW $30 \mathrm{~cm}$ (Insulation) & 65.00 & 12.8 & \\
OSB & 30.00 & 6.2 & \\
Gypsum & 45.00 & 11.5 & \\
Timber Frame (38/230 mm) & 55.00 & 20 & \\
SUM & $\mathbf{2 9 5 . 0 0}$ & $\mathbf{8 2 . 6}$ & Area \\
Roof & Cost $/ \mathrm{m}^{2}$ & Weight $/ \mathrm{m}^{2}$ & \\
\hline Vegetation (10 cm) & 56.00 & 64.5 & \\
Sealing (Bitumen) & 75.00 & 20 & \\
OSB (Particle Board) & 30.00 & 6.2 & \\
MW 40 cm (Insulation) & 86.00 & 16 & \\
OSB & 30.00 & 6.2 & \\
Gypsum & 45.00 & 11.5 & \\
Timber Frame (38/230 mm) & 55.00 & 20 & \\
SUM (Real) & $\mathbf{3 7 7 . 0 0}$ & $\mathbf{1 4 4 . 4}$ & \\
\hline
\end{tabular}

$f 3$ represents the weight of the added construction. The $\bar{x}$ variable represents the combination of the design variables.

\subsubsection{Energy use}

The first objective is described in Eq. (3)

Ele $_{\text {delivered }}=\mathrm{Q}_{\mathrm{c}}+\mathrm{Q}_{\mathrm{h}}+\mathrm{E}_{\mathrm{hv}}+\mathrm{E}_{\mathrm{la}}-\mathrm{E}_{\mathrm{PV}}$

where $Q_{c}$ represents cooling loads, $Q_{h}$ represents heating loads, $E_{h v}$ represents auxiliary electricity of heating and cooling fans, $E_{\text {la }}$ represents auxiliary electricity of appliances and artificial lighting. The total energy use is substituted from the electricity generation by the PV represented by the $\mathrm{E}_{\mathrm{PV}}$. Each of the heating and cooling loads takes into account the Coefficient of Performance (COP), and the primary energy conversion, which is the preferred metric according to the EPBD directive. According to Eq. (3), electricity has been identified as the primary source of energy. Other sources of energy for heating, such as gas, are not counted since the heat pump is designed to be the primary source of heating and cooling. Even though gas boilers may be used in the existing building as the primary source of heating, it has not to be counted in this equation. The energy use is meant to be calculated for the extension only, and not for the whole building.

\subsubsection{Life Cycle Costing (LCC)}

The second objective represents the difference of Life Cycle Costing (dLCC) of the building between the design option $L C C_{i}$ and Life Cycle Costing of the Reference Building $L C C_{R B}$ as shown in Eq. (4). Life Cycle Costing is represented by Eq. (5), where IC represents the investment cost of the building materials, $\mathrm{RC}$ represents the replacement cost of the replicable items such as the windows and PV panels, MC represents the maintenance cost, OC represents the operational cost in Belgium by means of energy use, and finally, the $C$ represents a constant value of the construction and design cost. The symboli denotes the indexes for each design solution, while $j$ denotes the index for each design parameter.

$\mathrm{dLCC}=L C C_{i}-L C C_{R B}$

$\mathrm{LCC}=\sum_{\mathrm{j}=1}^{\mathrm{i}} \mathrm{IC}_{\mathrm{j}}+\sum_{\mathrm{j}=1}^{\mathrm{i}} \mathrm{RC}_{\mathrm{j}}+\mathrm{MC}+\mathrm{OC}+\mathrm{C}$

The method in which the LCC has been based on the European Standards EN 15459 and ISO 15688-5 for the international standards for property life-cycle costing $[59,60]$. The calculations have been made over a 30 years life span as recommended by the EPBD. Thus, each of the interest and discount factor with escalation rates, along 30 years, has been based according to the Belgian standards, which is equal to 0.078 and 15.43 , respectively. Those values are considered in the replacementRC, and operational costsOC [16], represented by the following Eqs. (6) and (7).

$a_{e}=1-\left(1+r_{e}\right)^{-n} / r_{e}$

$r_{e}=r-e / 1+e$

where $a_{e}$ is the discount factor taking in consideration, $e$ is the escalation rate of the energy price and life space $n$, and $r_{e}$ represents the real interest rater, which includes the effect of the escalation rate of energy prices.

In this research study, it is important to mention that the following conditions have been considered when calculating the difference in Life Cycle Costing (dLCC):

- To build on the rooftop of an existing building, their real costs include the demolition of an existing roof, infrastructure (vertical water piper and electricity), superstructure (walls, roof and windows), heating and sanitary system installation, and finally interior finishing and carpentry. However, in this study, the cost of the superstructure (walls, roof, and windows) has only been calculated in the LCC calculations. 
- The LCC of the superstructure (Walls, Roof, and Windows) represents more than $40 \%$ of the Global LCC of the whole building according to construction values in Brussels, which remains of great significance and interest compared to the Global Cost of the whole building.

- Each of the maintenance and constant costs (including labor cost) are excluded since those factors are given the same value in the RB and each design option. On the contrary, each of the initial, replacement, and operational costs are calculated and makes a difference in the final value of the dLCC.

\subsubsection{Weight of construction}

The last objective is represented by Eq. (8), which calculates the weight of the added construction. From a structural point of view, there are several factors that affect the structural performance of a particular building, such as the dead load, live load, snow, wind, and seismic loads. According to the variable load, the structure of the added floor is designed. However, in this research, we are only concerned with the dead load of the added storey, since each of the live loads, wind, snow and seismic loads would be given the same values. Thus, the lighter the building is, the safer it is to be built on the rooftop of an existing building, taking in consideration the limited capacity of the existing foundation and soil to hold more weight [6]. The dead load is calculated by adding the weight of each component of the roof stacking module.

$D L=\sum_{j=1}^{i} W_{j}+R_{j}+F_{j}+G_{j}+P V_{j}$

where $W_{j}$ represents the weight of the wall, $R_{j}$ is the weight of the roof, $F_{j}$ is the weight of the floor, $G_{j}$ is the weight of the windows, and finallyPV $\mathrm{V}_{\mathrm{j}}$ is the weight of the added PV modules.

Remarkability, the same rule of calculating the LCC goes for calculating construction weight. In this research, the weight refers to the superstructure only rather than the total weight of the added building. However, the reason behind not calculating the difference in the added weight (similar to the difference in LCC), is due to the lack of precise estimates of the real weight of existing construction in this research. Therefore, and first, it was not possible to generate a difference in construction weight. Second, the weight of the construction is calculated in $\mathrm{Kg} / \mathrm{m}^{2}$ rather than $\mathrm{N} / \mathrm{m}^{2}$. The weight of the added superstructure is calculated separately by adding the weight of the construction components without further unit conversions, which is also simpler to understand for the different stakeholders in the decision-making process.

\subsection{Variables selection and grouping}

In this research, there are three main categories of variables as follows: envelope, system, and renewable energy. Given the specific characterization of roof stacking buildings, being placed on the rooftops of existing buildings does not give a great chance to vary between different active systems. Thus, there are very limited parameters that could be changed in the system, i.e. heating, cooling, and mechanical ventilation, from the design perspective. This change can take place by either connecting the added construction with the existing system or by providing an additional and separate system. Existing houses in Belgium (those dates back to WWII) do not have high energy efficient systems unless it has been renovated. Given the scope of this research, there is no aim to propose neither a renovation system for the building nor the system. Thus, a detached heat pump and mechanical ventilation with heat recovery have been identified. The specification of both the heat pump and ventilation system is set as a boundary condition to the reference building in the simulation model.

Building's envelope of the new construction is prone to a wide variety of building materials, including walls, roof, windows, and their specifications. The same goes for adding renewable energy sources when it comes to the number of photovoltaic (PV) panels, area, tilt angle, and orientation. It is important to highlight that the application of the developed methodology is not limited to the selected variations. Instead, it is possible to include all categories in the simulation whenever it is application and concerned with the decision-making process.

Design Variables of the building envelope are concerned with three main sections of the superstructure of the building: wall section, roof section, and windows. Table 4 shows the wall and roof section configurations and specifications. In this research, only the insulation for each section is considered as the main variable, in terms of type and thickness. The other layers are kept the same so as not to change their minimum thermal performance and to comply with passive house standards.

As shown in Table 3, four different types of insulations are examined: EPS, Cellulose, Mineral Wool (MW), and Wood Fiber (WF). The choice of insulation materials returns back to the common practices in the Belgian construction market. The thermal specifications of insulation materials, in terms of thermal conductivity, heat capacity, and density, have been identified based on the standard EN ISO 10456 [55]. The weight of the added construction is calculated based on the density of the building materials composing the envelope section. The average prices of the building materials have been identified based on the database of the Belgian construction works for 2017 entitled "Bordereau des Prix Unitaires." The minimum thicknesses of the insulation materials for both the wall and roof sections have been identified to comply with the passive house standard, which requires a minimum Uvalue of $0.15 \mathrm{~W} / \mathrm{m}^{2} \mathrm{~K}$ for the wall section and $0.10 \mathrm{~W} / \mathrm{m}^{2} \mathrm{~K}$ for the roof section. Therefore, a minimum thickness of $240 \mathrm{~mm}$ has been assigned for both the wall and roof insulations. For both the wall and roof section, a uniform step of $4 \mathrm{~cm}$ has been given as the parametric variation with a maximum of 5 steps for the wall section and 7 steps for the roof section.

Windows parameters vary under two categories: glazing type and ratio. In the first category, two different glazing types have been examined; the first is triple glazing with argon filling with a thickness of $36 \mathrm{~mm}$ and $\mathrm{U}$-value of $0.75 \mathrm{~W} / \mathrm{m}^{2} \mathrm{~K}$, while the second is also triple glazing with argon filling but with a thickness of $44 \mathrm{~mm}$ and $\mathrm{U}$-value of $0.6 \mathrm{~W} / \mathrm{m}^{2} \mathrm{~K}$. In the latter category, WWR changes from $20 \%$ as the minimum ratio that secures adequate daylighting for the indoor spaces, up to $90 \%$. Both variations are applied to the northern and southern facades for both rooms.

In this research, the minimum requirements of each of the fire resistance class REI and the weighted sound reduction index Rw [dB], have been taken into consideration and calculated based on EN 13501-2 [61], and EN ISO 140-1 and EN ISO 717-1 [62,63] respectively. According to the Belgian standards, the required fire resistance of building materials is relative to the height of the building, which is classified into a low, medium, and high rise. In this research, it is assumed that the added floor would rise or remain the existing building under the medium height building, which ranges between 10 and $25 \mathrm{~m}$ in height.

\section{Multi-Objective parametric analysis (MOPA)}

The proposed Multi-Objective Parametric Analysis (MOPA) for the assessment of the cost-optimal, zero-energy, and lightweight construction has been applied to the developed roof stacking RB, in which optimal design solutions that follow the Belgian passive house standards are identified. MOPA has been carried out on three stages. The first stage conducts a parametric analysis of the superstructure's building components separately (walls, roof, and windows). For running a parametric simulation on one group (e.g., wall), the other groups (e.g., roof and windows) are set on their 
Table 4

Case study superstructure's design variations.

\begin{tabular}{|c|c|c|c|c|c|}
\hline \multicolumn{6}{|l|}{ GROUP 1} \\
\hline $\begin{array}{l}\text { Wall Insulation } \\
\qquad\left(\text { Max. } 0.15 \mathrm{~W} / \mathrm{m}^{2} \mathrm{~K}\right)\end{array}$ & $\begin{array}{l}\text { Range of thickness } \\
\text { (uniform step } 0.04 \mathrm{~m} \text { ) }\end{array}$ & $\begin{array}{l}\text { U-values } \\
\left(\mathrm{W} / \mathrm{m}^{2} \cdot \mathrm{K}\right)\end{array}$ & $\begin{array}{l}\text { Weight } \\
\left(\mathrm{kg} / \mathrm{m}^{3}\right)^{*}\end{array}$ & $\begin{array}{l}\text { Investment cost } \\
\left(\text { Euros } / \mathrm{m}^{3}\right)^{* *}\end{array}$ & $\begin{array}{l}\text { Number of } \\
\text { Variables }\end{array}$ \\
\hline EPS & $0.24-0.40$ & $0.15-0.085$ & 30 & 300.00 & 20 \\
\hline Cellulose & (A total of 5 steps) & $0.15-0.092$ & 45 & 92.00 & \\
\hline Mineral Wool & & $0.15-0.082$ & 20 & 216.00 & \\
\hline Wood Fiber & & $0.15-0.097$ & 35 & 318.00 & \\
\hline \multicolumn{6}{|l|}{ GROUP 2} \\
\hline $\begin{array}{l}\text { Wall Insulation } \\
\qquad\left(\operatorname{Max} .0 .10 \mathrm{~W} / \mathrm{m}^{2} \mathrm{~K}\right)\end{array}$ & $\begin{array}{l}\text { Range of thickness } \\
\text { (uniform step } 0.04 \mathrm{~m} \text { ) }\end{array}$ & $\begin{array}{l}\text { U-values } \\
\left(\mathrm{W} / \mathrm{m}^{2} . \mathrm{K}\right)\end{array}$ & $\begin{array}{l}\text { Weight } \\
\left(\mathrm{kg} / \mathrm{m}^{3}\right)^{*}\end{array}$ & $\begin{array}{l}\text { Investment cost } \\
\left(\text { Euros } / \mathrm{m}^{3}\right)^{* *}\end{array}$ & $\begin{array}{l}\text { Number of } \\
\text { Variables }\end{array}$ \\
\hline EPS & $0.24-0.48$ & $0.10-0.077$ & 30 & 300.00 & 12 \\
\hline Cellulose & (A total of 7 steps) & $0.10-0.084$ & 45 & 92.00 & \\
\hline Mineral Wool & & $0.10-0.075$ & 20 & 216.00 & \\
\hline Wood Fiber & & $0.10-0.088$ & 35 & 318.00 & \\
\hline \multicolumn{6}{|l|}{ GROUP 3} \\
\hline $\begin{array}{l}\text { Window Type } \\
\left.\text { (Max. } 0.75 \mathrm{~W} / \mathrm{m}^{2} \mathrm{~K} \& \mathrm{~g} \text {-value } 50 \%\right)\end{array}$ & $\begin{array}{l}\text { Range of WWR } \\
\text { (uniform step 10\%) }\end{array}$ & $\begin{array}{l}\text { U-values } \\
\left(\mathrm{W} / \mathrm{m}^{2} \cdot \mathrm{K}\right)\end{array}$ & $\begin{array}{l}\text { Weight } \\
\left(\mathrm{kg} / \mathrm{m}^{2}\right)^{*}\end{array}$ & $\begin{array}{l}\text { Investment cost } \\
\left(\text { Euros } / \mathrm{m}^{2}\right)^{* *}\end{array}$ & $\begin{array}{l}\text { Number of } \\
\text { Variables }\end{array}$ \\
\hline $\begin{array}{l}\text { Triple glazing } \\
\quad(36 \mathrm{~mm}) \text { with Ar. filling }\end{array}$ & $\begin{array}{l}20 \%-90 \% \\
\text { (A total of } 8 \text { steps) }\end{array}$ & 0.75 & 30 & 140.00 & 128 \\
\hline $\begin{array}{l}\text { Triple glazing } \\
\quad(44 \mathrm{~mm}) \text { with Ar. filling }\end{array}$ & & 0.60 & & 160.00 & \\
\hline
\end{tabular}

default parameters (i.e., passive house setting). The second stage conducts a parametric analysis of the optimum design variables resulted from the first stage. The third and last stage conducts a parametric analysis on renewable energy resources in combination with the optimum design variables of the whole building's envelope resulting from the second stage.

In order to speed up the simulation process, the time step setting has been reduced from 2 , as the default value, to 1 . In principle, the simulation runs on an hourly basis. However, each hour is divided into smaller steps to result in the average performance (e.g., temperature or energy use) of a single hour. Reducing the simulated steps in one hour gives relatively less precise results. However, this research focuses on comparing different results with each other rather than giving a precise value of the building's performance. Thus, once optimal results are identified, it is recommended to rerun simulations with higher precision settings. The RB has been modeled and simulated using EnergyPlus via Ladybug and Honeybee plugins in Grasshopper. The values of annual energy use as a result of heating, cooling, and auxiliary electricity demands are assessed for direct electricity usage. Each simulation run takes between 8 and $10 \mathrm{~s}$ by using the "conduction transfer function" algorithm with one time-step per hour.

\subsection{First step: Parametric analysis for individual groups}

For each of the wall and roof sections, insulation type and thicknesses have been set as parametric variables for simulation. There are a total of 20 simulation runs for the wall section, and 28 simulation runs for the roof section, as shown in Figs. 5 and 6, respectively. A bi-objective parametric analysis has been carried out to examine the influence of insulation on energy use and the dLCC. The effect of the parametric variations has not been studied on the third design objective due to its negligible effect on the overall weight of construction.

The parametric analysis has been carried out on the basis of cross-referencing all design variables together, giving all possible options of design variables combinations. The outcomes are plotted on a 2D graph, where Pareto Front is identified mathematically in red color. Out of 20 options of the wall section design variables we get seven optimum results. Out 28 options of the roof section design variable, we get eight optimum results.

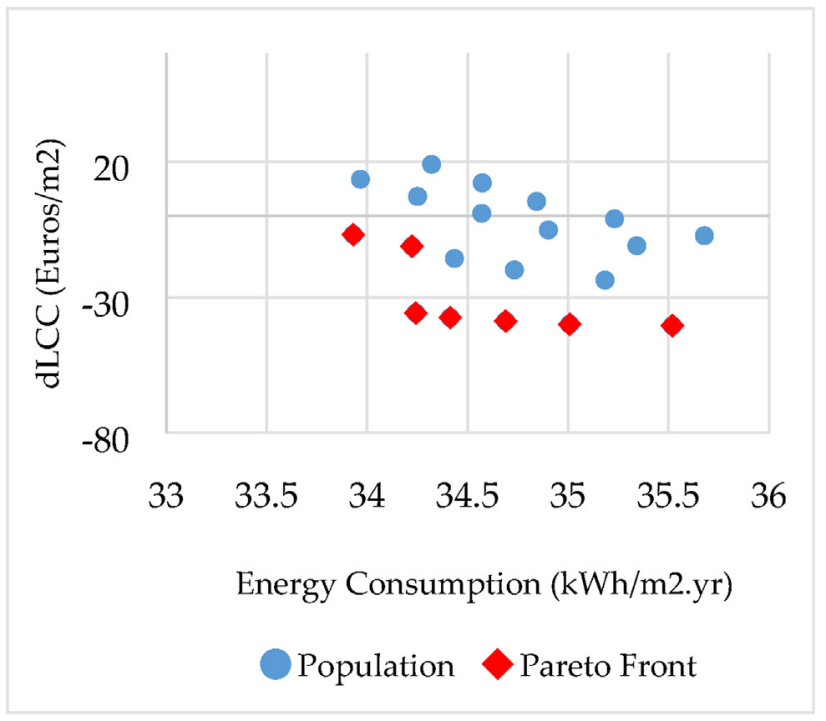

Fig. 5. MOPA on design variables of the wall section.

For windows, there are four different variables, namely: orientation, window ratio, glazing, and shading set points. The developed RB has two orientations: North and South. Each orientation has 8 different window ratios to be examined, which ranges between $20 \%$ and $90 \%$. Two different glazing types have been tested, and four different settings for shading setpoints have been identified based on global radiation. Therefore, as a result, there are 518 various design attributions that have been parametrically simulated.

Cross influencing has been done in the first stage based on selected solutions from the Pareto Front. The relation was inversely proportional. Then, in step 2, we cross influencing the optimal results again based on the new Pareto front. The use of Pareto Front solutions resulted in an effective cross influencing in stages 1 and 2. Moreover, the cross influencing depends on both the selected objectives and selected variables. e.g., some variables are inversely proportion wall and roof. e.g., some variables are directly proportional to the windows variable. 


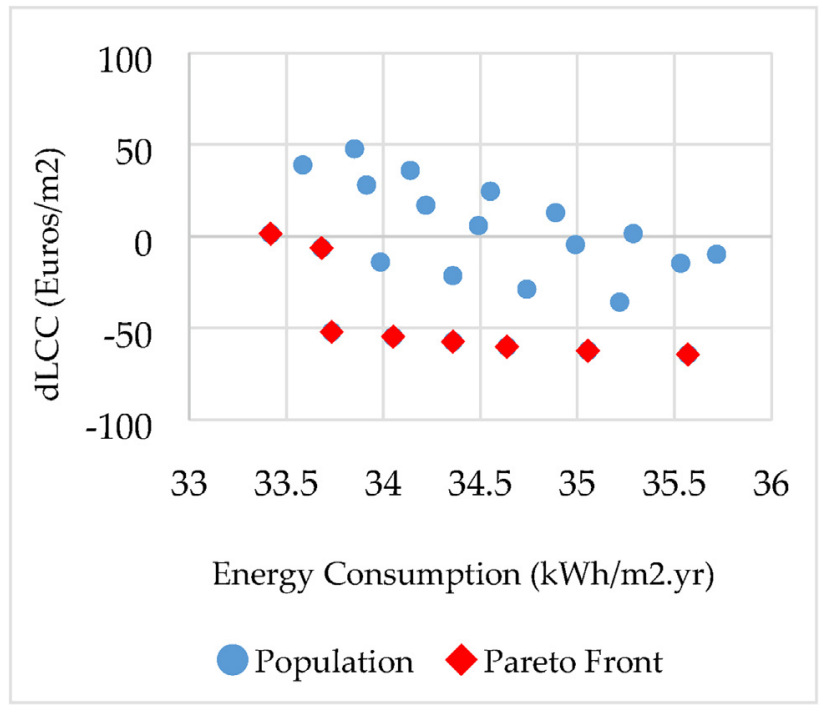

Fig. 6. MOPA on design variables of the roof section.

As illustrated in Fig. 7, the results have a significant variation in performance. The Pareto front seems non-conventional because the relation between energy consumption and LCC with windows parameters directly proportional. Thus, this variation is linear, which does not illustrate conflicting result that tends to give a distinct set of results as experienced with the opaque package. Compared to the windows configurations of the reference passive house, the more window ratio, the less performance is in terms of energy use, and LCC. Therefore, optimum results out of the 518 design option are three only according to the Pareto Front.

\subsection{Second step: Parametric analysis on optimum variables}

In the second stage, optimum design variables resulted from each group separately (wall, roof, and window) are analyzed together in one group. In this stage, there are a total of 168 simulations run as a result of cross-referencing the optimum variables of individual groups together. As in Fig. 8, the Pareto Front has a number of 23 optimum results. Therefore, it is possible to define a specific direction or pattern. First, it is found that glazing with higher performance does not improve the overall performance of the building. The type of glazing that has been set in the reference house is found to be more efficient. Second, the optimum insulation type is found to be the same for the wall and roof section. However, insulation thicknesses do not frequently match between walls and roof. Third, it has been found that minimum window ratios (20\%), with no shading devices, are the most efficient in terms of energy and cost for both orientations: the north and the south.

At this stage, several design variables are excluded, which significantly reduce the number of simulation runs needed in the next and last step of the MOPA. For instance, high window ratios, external shading, and glazing types are not included in the next simulation phases, in addition to two types of insulation out of four that are excluded in the next phase.

\subsection{Third step: Renewable energy integration}

The final stage aims to integrate onsite renewable energy resource to cover the energy use by the new construction as shown in Fig. 9. Combining renewable energy counts as an additional package, in which zero-energy target should be met. Similar to the previous step in finding optimal variables for the building envelope, the specifications of the PV is based on their availability in the Belgian market. Accordingly, one type of PV has been selected to be examined in this research work made of polycrystalline silicon modules, with a robust aluminum frame to withstand wind and snow loads up to $5400 \mathrm{~Pa}$. One PV panel has the dimensions of roughly 1.5 m length $\times 1 \mathrm{~m}$ width, which makes it of $1.5 \mathrm{~m}^{2}$ area with an efficiency of $16.69 \%$, and cost 900 Euros per panel.

In terms of design variations of PV panel, each of the orientation, tilt angle, and the number of panels are counted, not to men-

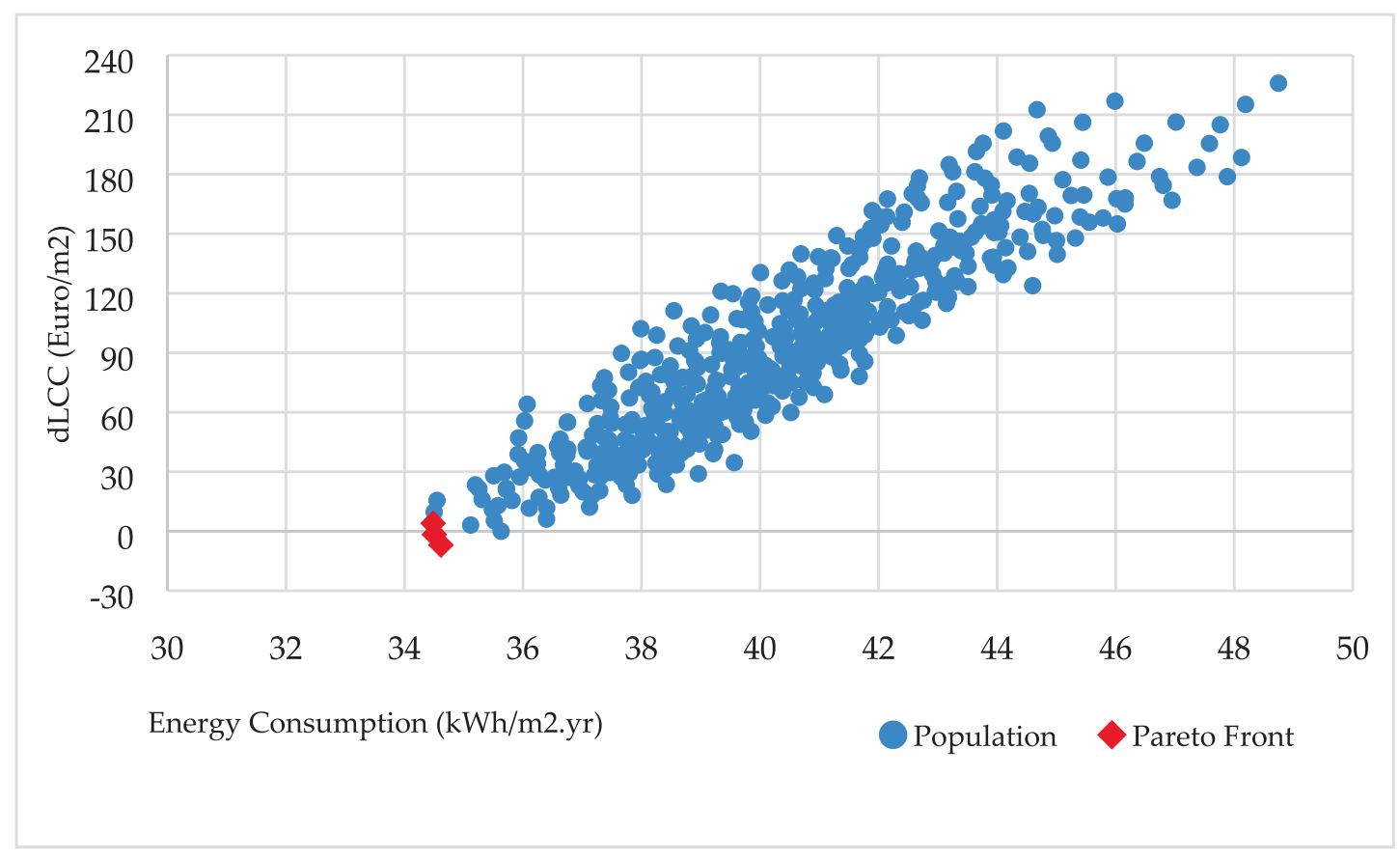

Fig. 7. MOPA on the design variables of windows. 


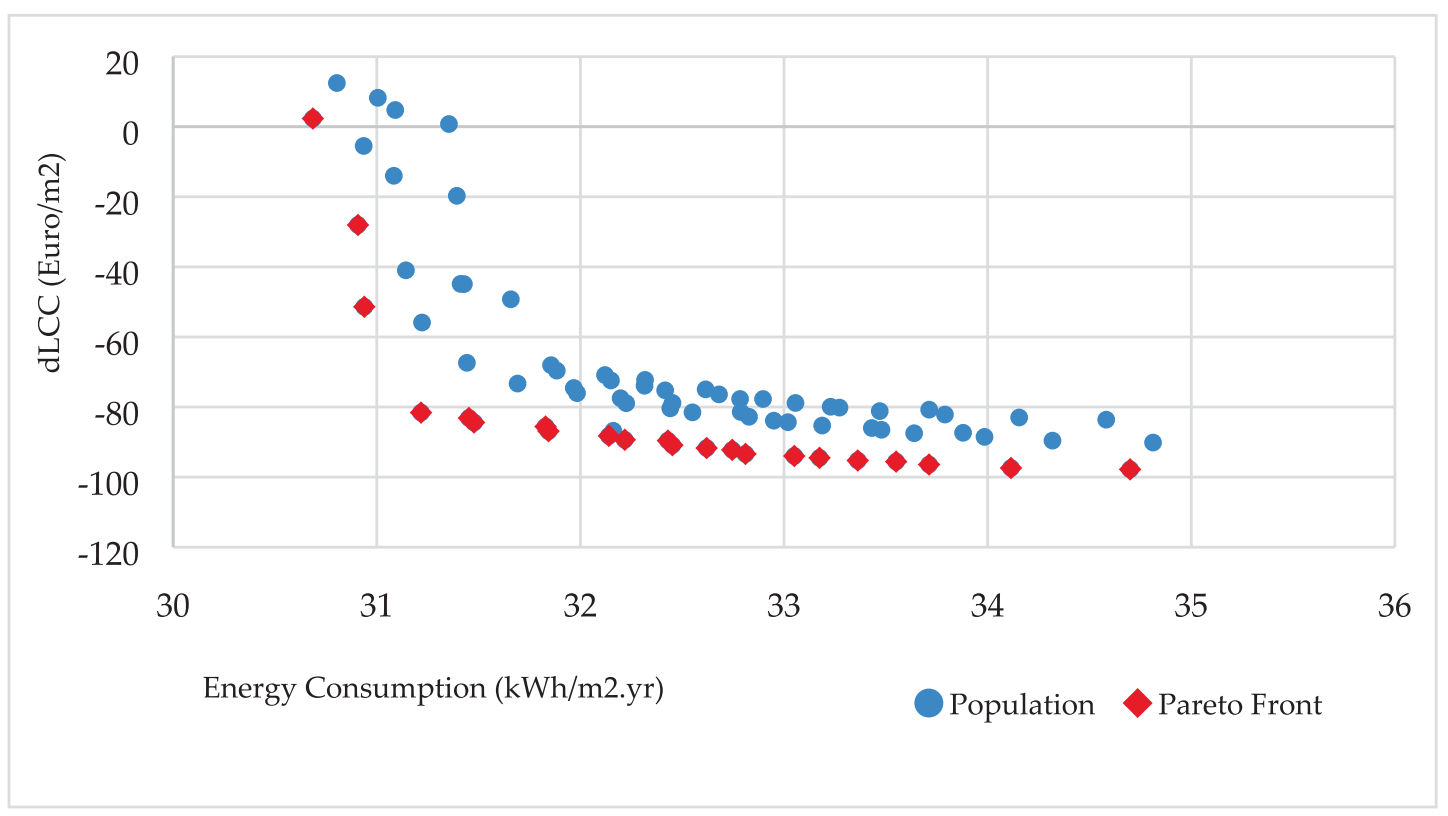

Fig. 8. MOPA on the optimum design variables of the combined groups.

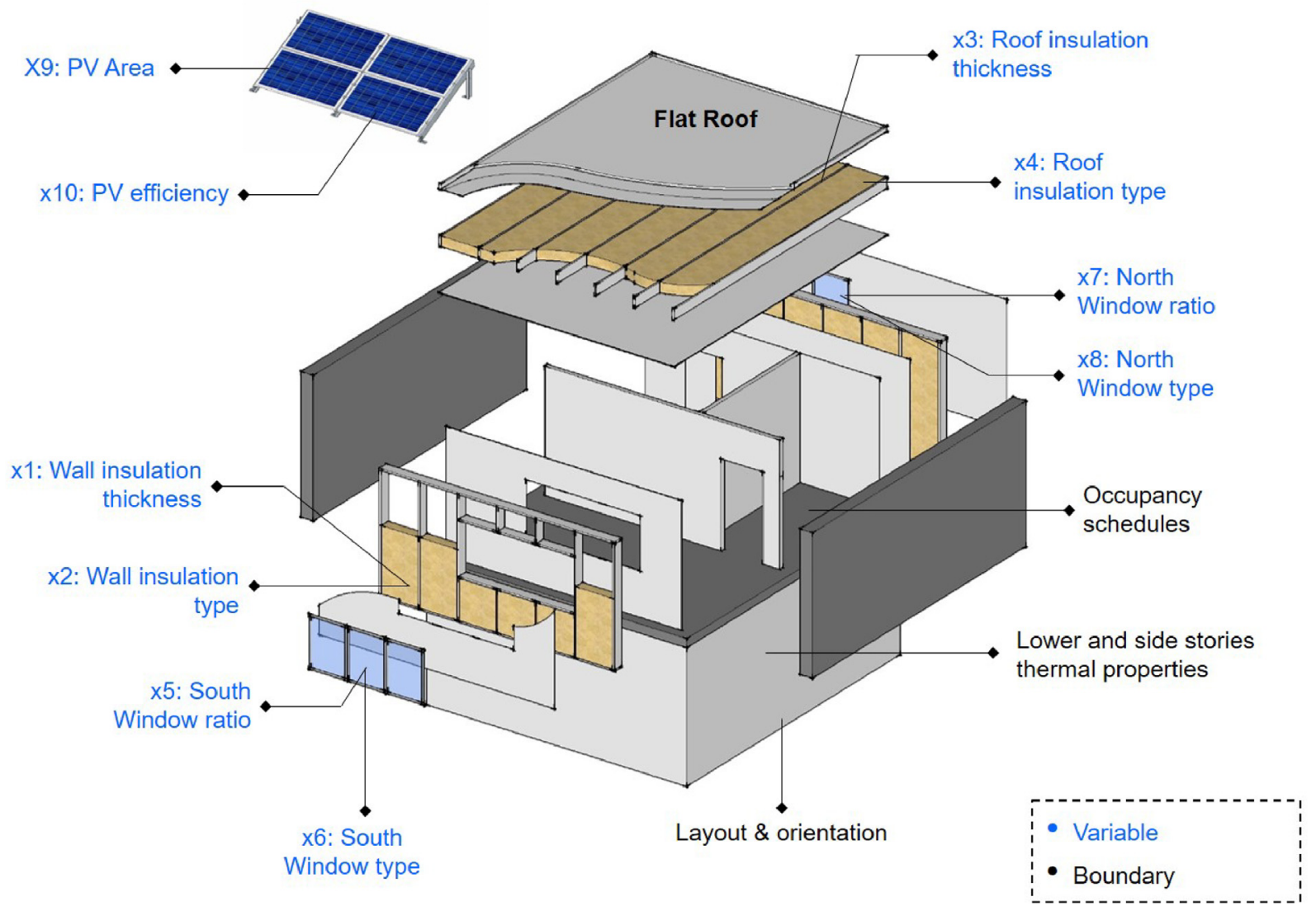

Fig. 9. The MOPA variables including the PV panels variables.

tion PV specifications, which has been identified as constant in this study. Yet, not all PV design variations have been taken into consideration in this research. Given the layout configuration of the case study, it is easy to determine the most efficient orientation and tilt angle based on the weather file of Brussels city. Thus, PV panels have been set up towards the south direction with $40^{\circ}$ degrees tilt angle. Accordingly, only the number of PV panels has been up as a design variable when integrating renewable energy resources. 
By changing the maximum number of PV panels, the total area ranges between 1.5 (equivalent to one PV panel) and $22.5 \mathrm{~m}^{2}$ (equivalent to $15 \mathrm{PV}$ panels) for the RB in this study. However, the more panels, the more cost and weight added to the building. Therefore, the last stage aims to conduct MOPA on all design objectives, which means that cost-optimal zero-energy results are targeted while seeking the least amount of PV panels on the rooftop to reduce the overall weight of construction on the rooftop.

Total energy use has been calculated after considering the amount of energy produced by the PV panels. Therefore, the value of the final energy use varies between positive $(+)$ and negative $(-)$. Positive values indicate that the building does not meet zero energy targets. While negative values represent zero-energy or positive energy buildings, which produces more energy than consumed. In terms of LCC calculations, first, PV panels initial cost is added to the overall initial cost of the building's envelope. Second, in case of producing more energy than consumed, the exceeded energy is assumed to be sold back to the grid with the same price of buying electricity. Thus, the sold energy prices are subject to inflation and discount rates calculations on the span of 30 years, which contributes to the overall LCC of the design option.

\section{Evaluation and selection}

\subsection{Cost-optimal zero-energy lightweight construction selection}

In this step, the results are illustrated in a 3D graph representing the three axes objectives: X-axis for energy use [ $\mathrm{kWh} / \mathrm{m}^{2} / \mathrm{yr}$.], Y-axis for dLCC [Euros/m2], and Z-axis for weight of construction $\left[\mathrm{Kg} / \mathrm{m}^{2}\right]$. Moreover, the results are divided into four quadrants, as previously explained in the methodology section. However, in this case, study, the four quadrants are illustrated based on the thresholds of the main design objectives: Energy use and dLCC. The thresholds are marked at the "Zero Points," where negative values represent either a cost-efficient or zero-energy building, or both. As shown in Fig. 10, the first quadrant refers to the solution space that lays in the cost-optimal zero-energy design solutions. The three rest quadrants may represent optimal solutions but for single design objectives.

In terms of the overall weight of construction, we found that all design options were heavier than the RB. This is because the higher building's performance, the more materials are added to the buildings, such as insulation boards, and the more PV panels are required, which contributes to the overall weight of construction. However, in the 3D graph, we aim to identify cost-optimal zeroenergy design options with the least construction weight, which leads to the next step of selecting optimum design variables.

\subsection{Optimum variables selection}

All design variables represented in the 3D graph are plotted in a parallel, coordinated graph, as shown in Figs. 11 and 12. The columns on the left side represent the range of design variables, while the right columns represent the objectives.

Table 5 gives all design options while highlighting the costoptimal design variables and their equivalent design objective results for each of the energy, cost, and weight of construction, which are marked in gray. All the selected cases are optimal result regarding energy use and LCC. So we ranked the results in the optimal solution space according to weight to allow designers to choose from a broader range of choices.

Throughout the parallel, coordinated graph, it is possible to select optimal design variables based on the following settings:
- To select the cost-optimal zero-energy design options, all design objectives should have negative values, which start from 0 to $-30 \mathrm{kWh} / \mathrm{m}^{2} / \mathrm{yr}$. for energy use and from 0 to -200 Euros for the dLCC, as shown in Fig. 10.

- Out of the selected design options, there is a variety of construction weights, which represents the solution space of costoptimal zero-energy and lightweight construction.

- From the design variables columns, it is possible to identify new boundaries. For instance, it is possible to choose one type of insulation, a certain thickness, or the number of PV panels, which lie within the optimal solution space.

\section{Discussion}

\subsection{Summary and main findings}

This research work introduces a new methodology that aims to achieve cost-optimal zero-energy lightweight construction. This research contributes to the field of multi-objective optimization. However, the developed methodology in this research utilizes no optimization algorithms. Instead, a novel method has been developed, denoted as MOPA, "Multi-Objective Parametric Analysis." As comprehended from the denotation, the methodology heavily relies on parametric analysis, using simulation, to find optimum results for multiple design objectives. This novel methodology significantly reduces the time and effort required to achieve multiobjective optimal results compared to optimization algorithms. We were able to surpass the complexity of using and understanding optimization algorithms, not to mention the paradox of choosing the right algorithm for the right design objective [45,64].

Even though roof stacking buildings have been witnessed widely in Brussels and Europe, we found no reference building developed for such type of construction. Thus, in this research, we have developed, first of its type, new theoretical Reference Building (RB) for roof stacking housing module. The RB has been developed based on two references. The first is a reference house, where building configurations and performance have been identified for the envelope and system. Second, the layout and geometry for the RB have been referred to as a common housing typology in Brussels. Applying Belgian passive house standards on the RB returns back to the regulation in Brussels Capital Region, which states that as of 2015 , all new construction should comply with passive house standards?

The economic feasibility objective has been studied by means of LCC on a 30 years' time-span, where the design objective referred to the difference in the LCC between the RB and the design option, denoted as dLCC. However, it is important to highlight that this research is not meant to calculate the Global Cost (GC) of the whole building. Instead, the LCC calculations are subjected to specified building elements, namely superstructure (Walls, Roof, and Windows). The initial cost of the superstructure's element represents $42 \%$ of the Global Cost of the roof stacking building, which includes demolition, infrastructure (vertical water piper and electricity) and superstructure elements, heating, and sanitary system, interior finishing and carpentry. Moreover, when calculating dLCC, each of the maintenance and labor costs has been excluded, since they have the same value for each of the RB and a given design option.

The same method of calculating the LCC goes for the calculation of construction weight. The weight of superstructure elements has been calculated instead of the weight of the whole roof stacking. However, we have not performed a difference in construction weight between the RB and a design option for a couple of reasons. First, we had no precise numbers for the actual not theoretical construction weight of the RB. Second, total variable loads (including live, wind, snow, and seismic loads) would have to be considered if the whole weight of the construction is calculated. Instead, when 


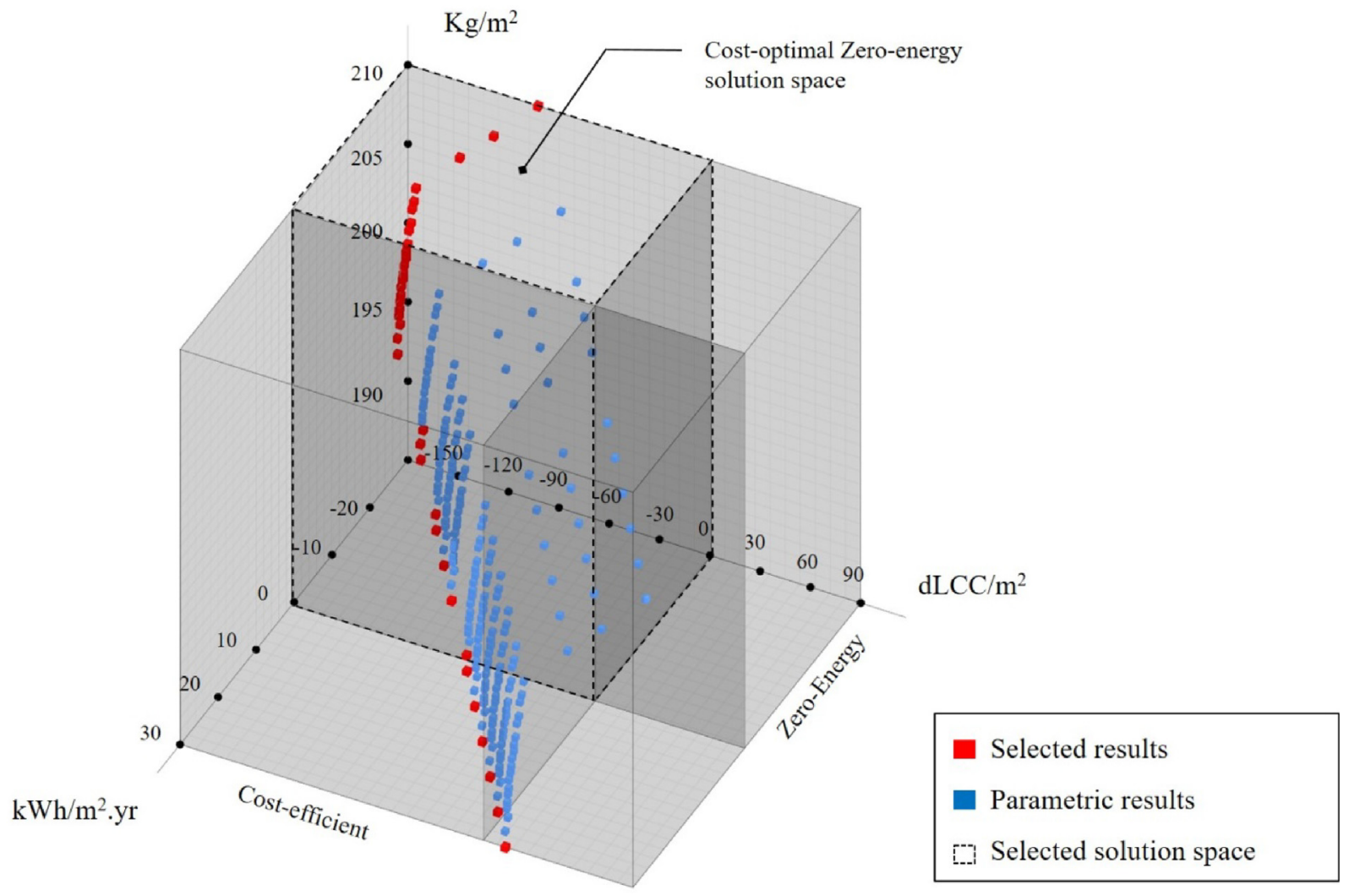

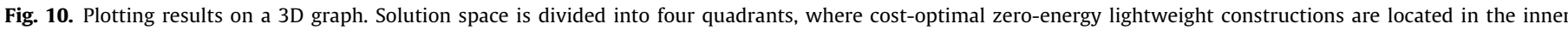
quadrant as marked on the Figure.

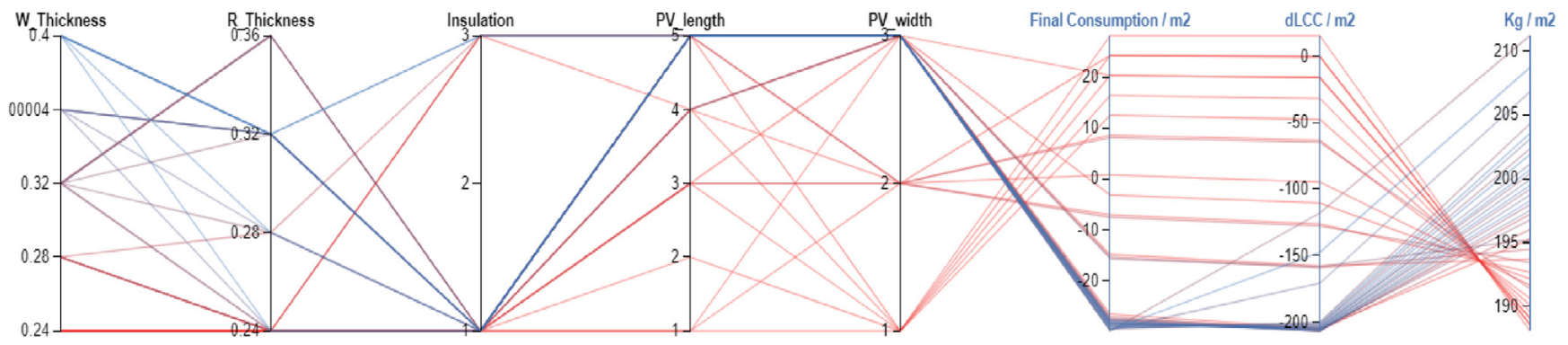

Fig. 11. Parallel coordinated graph for all design options.

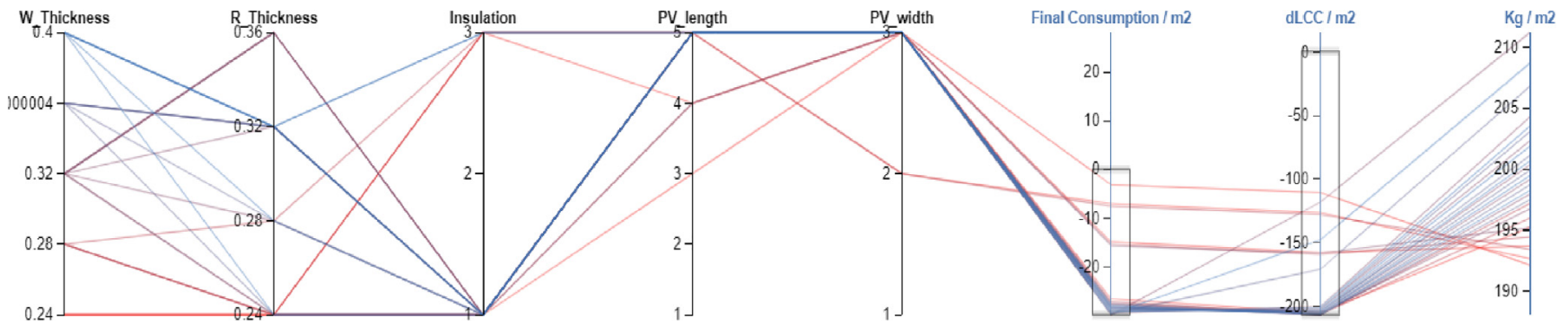

Fig. 12. Parallel coordinated graph for selected design options. 
Table 5

Cost-optimal zero-energy design options.

\begin{tabular}{|c|c|c|c|c|c|c|c|}
\hline \multicolumn{5}{|c|}{ VARIABLES } & \multicolumn{3}{|c|}{ OBJECTIVES } \\
\hline Wall & Roof & Insulation & PV Length & PV Width & kWh/m2/yr. & dLCC / m2 & $\mathrm{Kg} / \mathrm{m} 2$ \\
\hline 0.36 & 0.32 & Cellulose & 5 & 3 & -29.30 & -201.98 & 203.06 \\
\hline 0.32 & 0.36 & Cellulose & 5 & 3 & -28.75 & -203.62 & 201.11 \\
\hline 0.4 & 0.32 & Cellulose & 5 & 3 & -28.21 & -206.57 & 198.71 \\
\hline 0.36 & 0.32 & Cellulose & 5 & 3 & -27.75 & -206.63 & 197.51 \\
\hline 0.32 & 0.32 & MW & 5 & 3 & -29.94 & -117.82 & 211.17 \\
\hline 0.4 & 0.28 & Cellulose & 5 & 3 & -29.51 & -200.01 & 204.26 \\
\hline 0.36 & 0.28 & Cellulose & 5 & 3 & -29.01 & -201.98 & 202.31 \\
\hline 0.32 & 0.28 & Cellulose & 5 & 3 & -28.52 & -204.02 & 200.35 \\
\hline 0.28 & 0.28 & Cellulose & 5 & 3 & -28.26 & -205.63 & 199.15 \\
\hline 0.4 & 0.24 & MW & 5 & 3 & -27.91 & -206.49 & 197.95 \\
\hline 0.36 & 0.24 & Cellulose & 5 & 3 & -27.47 & -205.32 & 196.75 \\
\hline 0.32 & 0.24 & Cellulose & 4 & 3 & -15.38 & -159.14 & 194.47 \\
\hline 0.32 & 0.24 & Cellulose & 4 & 3 & -15.71 & -158.15 & 195.22 \\
\hline 0.28 & 0.24 & Cellulose & 4 & 2 & 0.76 & -94.71 & 191.67 \\
\hline 0.28 & 0.24 & Cellulose & 3 & 3 & -3.15 & -110.43 & 192.18 \\
\hline 0.28 & 0.24 & Cellulose & 5 & 2 & -7.06 & -126.15 & 192.69 \\
\hline 0.28 & 0.24 & Cellulose & 4 & 3 & -14.90 & -157.60 & 193.71 \\
\hline 0.28 & 0.24 & Cellulose & 2 & 3 & 8.12 & -64.79 & 191.40 \\
\hline 0.28 & 0.24 & MW & 5 & 2 & -7.54 & -127.69 & 193.44 \\
\hline 0.28 & 0.24 & Cellulose & 5 & 3 & -27.60 & -206.33 & 197.20 \\
\hline 0.24 & 0.24 & Cellulose & 1 & 1 & 28.20 & 15.36 & 188.09 \\
\hline 0.24 & 0.24 & Cellulose & 2 & 1 & 24.28 & -0.36 & 188.60 \\
\hline 0.24 & 0.24 & Cellulose & 1 & 2 & 24.28 & -0.36 & 188.60 \\
\hline 0.24 & 0.24 & Cellulose & 3 & 1 & 20.36 & -16.08 & 189.11 \\
\hline 0.24 & 0.24 & MW & 1 & 3 & 20.36 & -16.08 & 189.11 \\
\hline 0.24 & 0.24 & MW & 4 & 1 & 16.44 & -31.81 & 189.62 \\
\hline 0.24 & 0.24 & MW & 2 & 2 & 16.44 & -31.81 & 189.62 \\
\hline 0.24 & 0.24 & Cellulose & 5 & 1 & 12.52 & -47.53 & 190.13 \\
\hline 0.24 & 0.24 & Cellulose & 3 & 2 & 8.60 & -63.26 & 190.65 \\
\hline 0.24 & 0.24 & Cellulose & 2 & 3 & 8.60 & -63.26 & 190.65 \\
\hline 0.24 & 0.24 & Cellulose & 3 & 2 & 8.12 & -64.79 & 191.40 \\
\hline 0.24 & 0.24 & Cellulose & 2 & 3 & 8.12 & -64.79 & 191.40 \\
\hline 0.24 & 0.24 & Cellulose & 5 & 3 & -27.14 & -206.31 & 196.00 \\
\hline
\end{tabular}

counting for specific building components, it would be simple enough to count the weight of each building component, which partially represents the dead load of the new construction.

When applying MOPA on the roof, stacking RB, we found the following:

- Using cellulose for insulation in the wall and roof sections was found to provide the most efficient results in terms of financial viability. The second recommended insulation material would go for Mineral Wool with a minimum of $40 \mathrm{~cm}$ thickness of insulation for each of the wall and roof sections. Mineral Wool is recommended for higher energy efficiency measures, though associated with higher cost.

- The relation between WWR and each of energy and financial efficiency is directly proportional, which is illustrated by the linear relationship between energy use and dLCC. In terms of energy use, it was found that the bigger the area of the window, the more heat losses is accompanied. Also, the cost of one square meter of the wall section of a RB is $€ 295$, which is equivalent to $45 \%$ of the rough cost of one square meter of the window, which is $€ 650$.

- In the contrary, the relationship between WWR and construction weight is inversely proportional. The more window ratio is the less construction weight. This is due to the weight difference between one square meter of glazing that is equal to $30 \mathrm{Kg}$, which is equivalent to $36 \%$ of the rough weight of one square meter of a wall section, for example, that is equal to $82.6 \mathrm{Kg}$.

- Although minimal window ratios are recommended for costoptimal and energy-efficient measures, it is important to ensure that windows provide the minimum requirement for daylighting to the indoor spaces.

\subsection{Internal validation}

Through this research, it was possible to make an internal comparative analysis between the objective results from the parametric simulation of a combination of two groups separately and combined (e.g., walls and roof). In the parametric simulation process, the number of cross-referenced design parameters of the mixed groups is equal to 560 simulation runs, which represents all possible design options for the opaque surface of the building envelope. Whereas the number of cross-referenced design parameters of the two separated groups is equal to 48 simulation runs in the first step, and 56 simulation runs, for optimum design variables, in the second step. In this method, a total of 104 simulation runs is required to obtain optimum results for the opaque surface of the building envelope.

The results of both methods are presented in Fig. 13 in parallel with each other. The results show that when subjecting Pareto Front of both approaches, they give the same Pareto curve concern- 


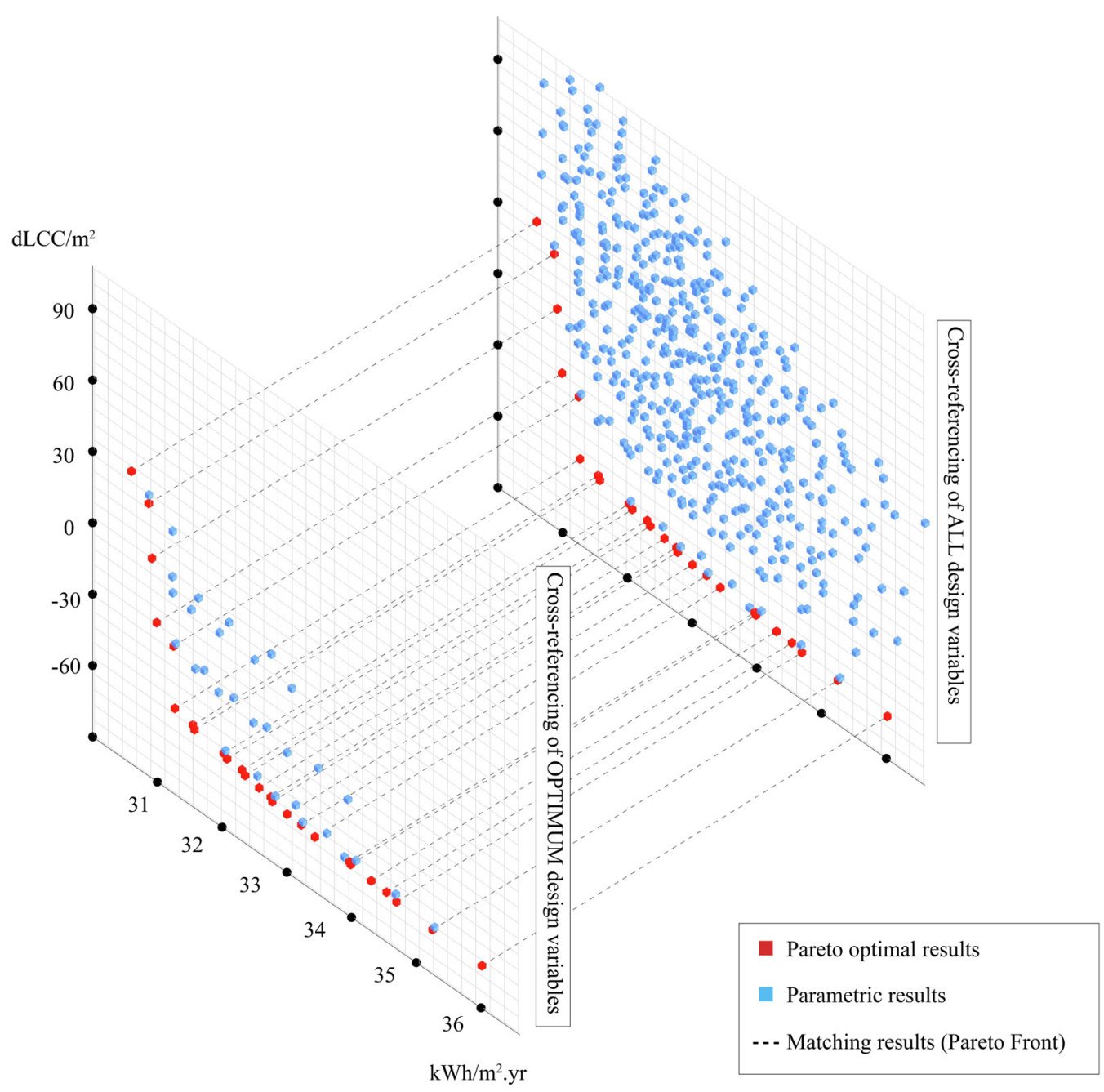

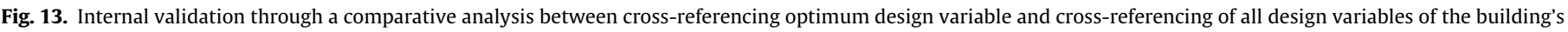
envelope opaque surface.

ing the same optimum design variables. Thus, it is possible to reduce $82 \%$ of simulation time and efforts by applying a cascading parametric simulation.

\subsection{Strengths and limitations of this research}

The methodology developed in this research provides a new approach to achieve multi-objective design targets without employing optimization algorithms. We avoid the complexity and paradox of choosing the right algorithm, which is hard to determine for many building engineers. Accordingly, this methodology facilitates and provides an informed decision-making process to achieve multi-objective design targets. Moreover, the tools used in this methodology are increasingly used by architectural and engineering offices. Therefore, methodology application could be widely used, and not limited to skilful researchers. However, minimum expertise in using parametric simulation tools, such as Grasshopper and Honeybee tools, is required to be able to apply this methodology.

Given the powerful tools used in this research, it is possible to apply this methodology on bi-objective, as well as tri-objective design targets. For instance, if the given existing building has enough capacity to hold new stories without giving a great concern on the added weight, and then it is possible to exclude the construction weight objective from the very beginning. Moreover, design objectives are not limited to cost, energy, or construction weight. Design objectives could be expanded to include thermal comfort, daylighting, or Life Cycle Analysis (LCA) depends on the purpose of the study. The developed methodology has proven to reduce the time and effort needed to optimize multi-objective design targets by $60 \%$. According to the case studied in this research, a total of 689 simulation runs were required, compared to the optimization algorithm, which requires at least 1800 simulation runs for nine design variables.

Also, we conducted a comparative analysis between the newly developed MOPA, and optimization algorithms that are commonly used in building performance simulations. Four different optimization algorithms have been used in the study: HypE, SPEA2, RBFMOpt and NSGA-II. Each of HypE and SPEA2 are conducted using Octopus plugin, while RBFMOpt and NSGA-II multiobjective optimization algorithms are conducted using Opossum plugin (Optimization Solver with Surrogate Models) in Grasshopper. This comparative analysis aims to assess the performance of different optimization algorithms to solve a tri-objective design problem and to identify the qualities between using optimization algorithms and parametric analysis.

Fig. 14 shows the results of the comparative analysis, where Xaxis represents the number of simulation runs concerning Y-axis, which represents the median Hypervolume, based on five runs for the optimization algorithm. The algorithms are tested through 


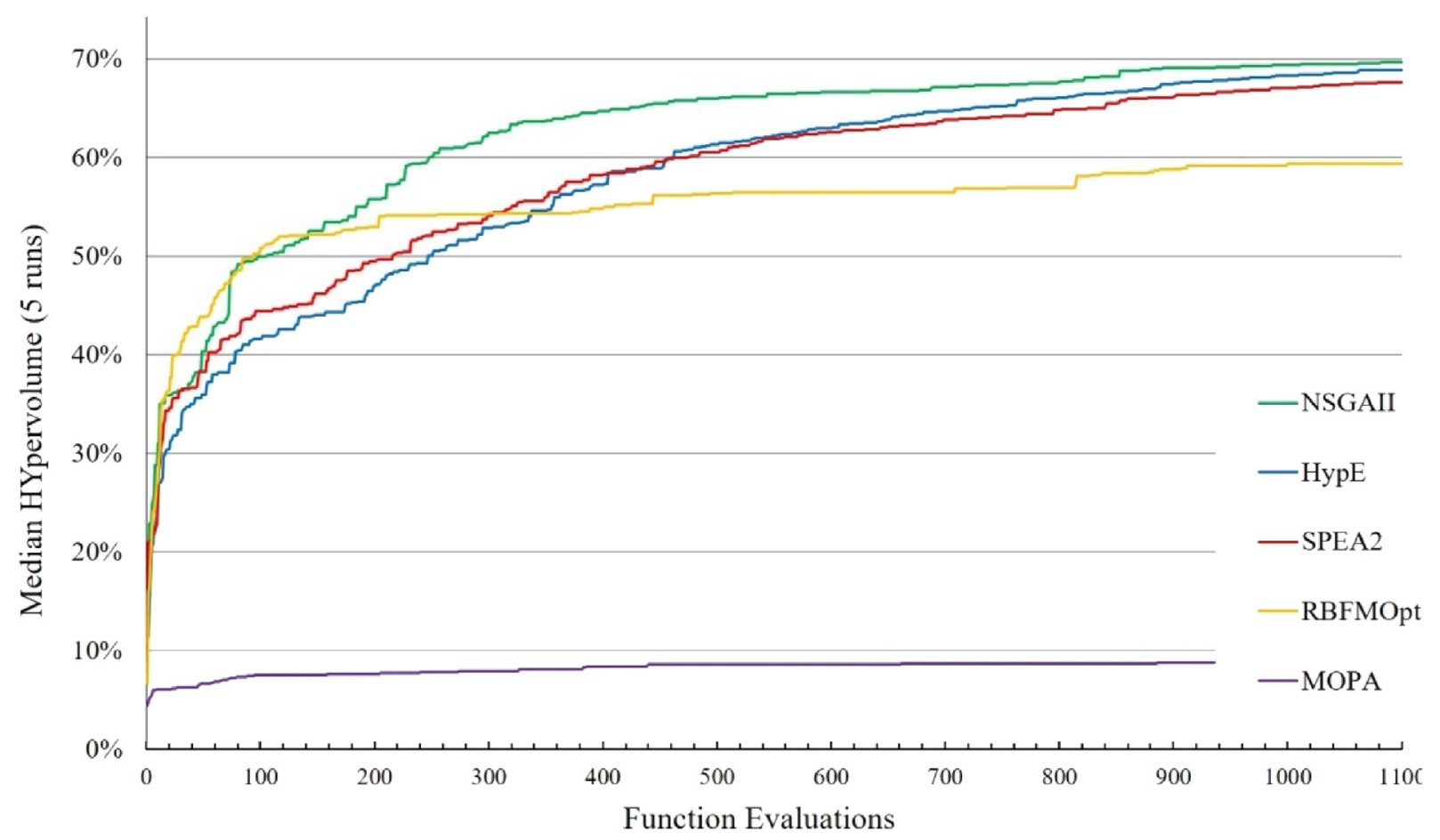

Fig. 14. comparison of the Hypervolume of MOPA against the four optimization algorithms.

five runs, which is different from the MOPA. Optimization algorithms are non-deterministic, whereas MOPA is deterministic. This means that MOPA gives the same results every time. The Hypervolume is normalized between 0 , being the worst performance, and 1 being the best performance.

The result of this graph shows that optimization algorithms provide better results after 1100 runs, the moment it reaches a stable value. However, when a closer look is given to the results, it shows that optimal solutions are not necessary zero-energy or cost-optimal, which is contrary to the results of MOPA. The reason is optimization algorithms provide the same weighing factor for all objectives, whereas MOPA depends on prioritizing objectives. In this research study, the priority has been given to the costoptimal zero-energy results, in favour of the overall weight of construction, which has been deterministically achieved as a result.

Lastly, this study developed the first of its kind, a theoretical passive RB for roof stacking in Brussels. By introducing this RB, we align with EBPD recast comparative framework methodology. Moreover, it is possible to provide general recommendations for cost-optimal zero-energy and lightweight construction for roof stacking buildings in Brussels. However, there are several limitations in this study that return to the boundary conditions of the case study. The LCC of the Global Cost (GC) has not been calculated in this research; instead, the LCC of the superstructure building elements (walls, roof, and windows) are only considered in the LCC calculations. We found that other variations that contribute to the GC, such as demolitions, infrastructure, and interior finishing, do not contribute to the optimization process in the developed methodology.

Other limitations have been applied in the simulation setups. To speed up the simulation process, we have reduced the hourly step from 6 to 2 in the simulation settings. Hourly steps identify the number of simulation runs in one single hour, which contributes to the precision of the simulation results. However, when conducting a comparative analysis (i.e., similar to MOPA), precision in the simulation results are not highly considered. Thus, when finalizing the simulation process seeking the identification of optimum energy-saving measures, it is urged to follow the recommended hourly steps. Finally, Design variations in the HVAC system have not to be studied in this research. The exclusion of the HVAC system in the design variables returns back to the boundary conditions of the project. However, it is recommended to include the HVAC system when considering the whole building of the analysis process.

\subsection{Future work and possible applications}

This research develops a universal methodology, which could be applied to several contexts and projects. Here we provide some recommendation for future applications on this methodology:

- Include other design objectives, such as LCA, thermal, or visual comfort. Moreover, for non-roof stacking buildings, when construction weight does not have an importance to the design objective, it is possible to target carbon emissions as a design target to comply with the Euro targets of achieving zerocarbon buildings.

- The methodology could be applied to other projects or real case studies instead of RB. Moreover, a comparative analysis could be conducted between several projects in several climate conditions (e.g., the Mediterranean or oceanic climates). More recommendations could be provided to other roof stacking projects based on the context and weather conditions.

- Given the limitation of studying only the performance of the added construction, it is recommended to examine the performance of the whole building, including the existing building, with eyes towards achieving zero energy. Moreover, examining the contribution of several HVAC systems to the reduction of energy use and LCC. The inclusion of the HVAC system could be studied with a complete framework for renovating the existing building. 
- Future work will conduct a comparative analysis between parametric analysis and optimization algorithms. Comparative analysis should give precise estimations on the needed time run simulations and achieve multi-objective optimized design variables.

- Finally, a usability test is recommended to be carried out with building engineers and decision-makers. The purpose of the usability test is to examine the ease of use, and the possibility to examine real case problems. The usability test should aim to improve the methodology in later stages.

\section{Conclusion}

In the EU and the international community, it has been of great interest to achieve zero-energy and carbon-neutral buildings. Under the shed of this interest, there have been several investigations and research in the field of optimization to achieve costoptimal zero-energy buildings. Accordingly, this research aims to add a novel contribution by developing a methodology that facilitates the decision-making process for cost-optimal and zero energy buildings. This methodology has been applied specifically on a newly developed RB for roof stacking buildings, where lightweight construction has been set as a third design objective.

The developed methodology is composed of the three main stages: modeling setup, parametric simulation, and finally, evaluation and selection. Each stage is composed of several minor steps. When applying the methodology on a case study, we reached the following conclusions:

Energy and financial performance do not necessarily contradict each other. For instance, when running parametric simulations for building's superstructure elements (walls, roof, and windows), the energy and financial performance of windows variables differed from the other building elements. The relationship between window ratio and design objectives (Energy use and dLCC) was directly proportional. The more area was given to the window, the more cost and energy it consumes.

It is more efficient to apply minimum window ratios taking into consideration achieving adequate daylighting for indoor spaces. Moreover, for small window ratios, there is no need to have external shadings. However, in case of having bigger window ratios, it is recommended to install exterior shading elements (e.g., blinds) to reduce the heat gains during the summer, and passive cooling from the sky during the night in winter.

The financial efficiency of the added PV panels is highly associated with several factors, which have to be identified by the boundary and local conditions. Thus, several considerations have to be taken when adding PV panels during the calculations, such as local regulations in terms of the local tariffs, more precisely the selling price of surplus energy, and, therefore, the calculations method during simulations. Moreover, the maximum roof capacity to hold PV panels in accordance with other installations (HVAC system, or solar heaters), in addition to their dimensions and arrangements on the rooftop.

It is possible to achieve a plus-energy building with high economic viability. Surplus energy production could be used either for the rest of the building, with an aim towards achieving zeroenergy targets, for the whole building, or to sell it to the grid. However, it is important to mention that either option would require, first of the all, to alter the calculation method, and therefore the outcome of the results of multi-objectivity of the parametric simulation process.

Early in the calibration process of the RB, it is essential to consider what so-called the "Heat Theft" in the context of having neighboring buildings, which happens as the result of either gaining or losing heat through the neighboring walls. Therefore, it has been set up as a calibration parameter.
In the process of MOPA, it is expected to have results that do not satisfy design objectives in the early simulation phases. The selection of the optimum results is expected to be achieved in the later stages of the parametric analysis. Moreover, choosing optimal design variables and solutions are closely tight with the available building materials and system in the market. In the case of bringing building components from abroad, it is essential to include the associated transportation costs, which will consequently affect each of the initial, or replacement costs, or both.

Finally, compared to previous research, parametric simulation is carried out in this methodology instead of optimization. Running parametric analysis yields to better decision-making, since it does not only analyze the relationship between the variable input results output, it is possible to illustrate Pareto Fronts and carry out trade-offs between design variables combinations in relation with multiple design objectives. Thus, parametric analysis was found to reduce the number of analysis steps in the decisionmaking process while providing robust results for multi-objective design targets. Moreover, avoiding using sophisticated tools or methods, such as optimization algorithms, scripting software (e.g., MATLAB), or EnergyPlus simulation engine interface) encourages a wide range of users to use and apply such methods, and therefore takes a step forward in achieving cost-optimal zeroenergy buildings.

When introducing this methodology, it is important not to undermine or underestimate the importance of optimization algorithms in building energy simulations. We instead aim to present a simplified method, which uses not optimization algorithms, to find optimal design solutions for multi-objective design targets, explicitly for small and mid-size projects with discreet design variables.

\section{CRediT authorship contribution statement}

Mohamed Amer: Conceptualization, Data curation, Formal analysis, Investigation, Methodology, Software, Validation, Visualization, Writing - original draft. Mohamed Hamdy: Conceptualization, Methodology, Writing - original draft, Validation, Visualization. Thomas Wortmann: Methodology, Software, Validation, Visualization. Ahmed Mustafa: Software, Data curation, Validation, Visualization. Shady Attia: Conceptualization, Data curation, Funding acquisition, Methodology, Project administration, Resources, Supervision, Validation, Writing - review \& editing.

\section{Declaration of Competing Interest}

The authors declare that they have no known competing financial interests or personal relationships that could have appeared to influence the work reported in this paper.

\section{Acknowledgements}

This research was funded by a welcome grant provided by Liege University, which is gratefully acknowledged. This publication is part of the research project 2016-2020 entitled: DenCity Prototype: Concepts of Zero Energy Lightweight Construction Households for Urban Densification. Also, we would like to acknowledge the Sustainable Building Design (SBD) Laboratory at the University of Liege for the use of the monitoring equipment in this research and valuable support during the experiments and data analysis.

\section{Appendix A. Supplementary data}

Supplementary data to this article can be found online at https://doi.org/10.1016/j.enbuild.2020.110170. 


\section{References}

[1] H. Khatib, IEA World Energy Outlook 2011-A comment, Energy Policy 48 (2012) 737-743.

[2] Population Division (2015). World Population Prospects: The 2015 Revision, Key Findings and Advance Tables; United Nations, 2015.

[3] C. Bonifazi, M. Okólski, J. Schoorl, P. Simon (Eds.), International Migration in Europe : New Trends and New Methods of Analysis, Amsterdam University Press, Amsterdam, 2008, ISBN 978-90-5356-894-1.

[4] United Nations New Urban Agenda: Statement of financial implications (A/71/ 713), 2017.

[5] M. Papageorgiou, Optimal Vertical Extension: A study on costs and environmental impact for structural engineers. Master thesis, TU Delft: Netherlands, 2016.

[6] M. Amer, A. Mustafa, J. Teller, S. Attia, S. Reiter, A methodology to determine the potential of urban densification through roof stacking, Sustain. Cities Soc. 35 (2017) 677-691.

[7] M. Amer, S. Attia, ROOF STACKING: Learned Lessons from Architects, SBD Lab, Liege University, Belgium, 2017.

[8] M. Amer, S. Attia, Urban Densification through Roof Stacking: Case Study, Proceedings of the European Network for Housing Research (ENHR) Annual Conference 2018, Uppsala University, Uppsala, Sweden, 2018.

[9] M. Amer ,S. Attia,Timber construction methods for roof stacking: Classification and comparative analysis, 2018.

[10] K. Knoop, S. Lechtenböhmer, The potential for energy efficiency in the EU Member States - A comparison of studies, Renew. Sustain. Energy Rev. 68 (2017) 1097-1105.

[11] M.B. Piderit, F. Vivanco, G. van Moeseke, S. Attia, Net Zero Buildings-A Framework for an Integrated Policy in Chile, Sustainability 11 (2019) 1494

[12] M. Hu, Cost-Effective Options for the Renovation of an Existing Education Building toward the Nearly Net-Zero Energy Goal-Life-Cycle Cost Analysis, Sustainability 11 (2019) 2444.

[13] J. Shim, D. Song, J. Kim, The Economic Feasibility of Passive Houses in Korea, Sustainability 10 (2018) 3558.

[14] European Commission, Directive 2010/31/EU Energy Performance of Building Directive (recast), Off. J. Eur. Union 153 (2010) 13-25.

[15] European Commission DIRECTIVE (EU) 2018/844, Off. J. Eur. Union 17 (2018).

[16] M. Hamdy, A. Hasan, K. Siren, A multi-stage optimization method for costoptimal and nearly-zero-energy building solutions in line with the EPBDrecast 2010, Energy Build. 56 (2013) 189-203.

[17] G.M. Mauro, M. Hamdy, G.P. Vanoli, N. Bianco, J.L.M. Hensen, A new methodology for investigating the cost-optimality of energy retrofitting a building category, Energy Build. 107 (2015) 456-478.

[18] M. Hamdy, K. Sirén, A multi-aid optimization scheme for large-scale investigation of cost-optimality and energy performance of buildings, J. Build. Perform. Simul. 9 (2016) 411-430.

[19] M. Hamdy, K. Sirén, S. Attia, Impact of financial assumptions on the cost optimality towards nearly zero energy buildings - A case study, Energy Build. 153 (2017) 421-438.

[20] M. Hamdy, A.-T. Nguyen, J.L.M. Hensen, A performance comparison of multiobjective optimization algorithms for solving nearly-zero-energy-building design problems, Energy Build. 121 (2016) 57-71.

[21] F. Ascione, N. Bianco, C. De Stasio, G.M. Mauro, G.P. Vanoli, A new methodology for cost-optimal analysis by means of the multi-objective optimization of building energy performance, Energy Build. 88 (2015) 78-90.

[22] F. Ascione, N. Bianco, C. De Stasio, G.M. Mauro, G.P. Vanoli, Multi-stage and multi-objective optimization for energy retrofitting a developed hospital reference building: A new approach to assess cost-optimality, Appl. Energy 174 (2016) 37-68.

[23] F. Ascione, N. Bianco, R.F. De Masi, G.M. Mauro, G.P. Vanoli, Energy retrofit of educational buildings: Transient energy simulations, model calibration and multi-objective optimization towards nearly zero-energy performance, Energy Build. 144 (2017) 303-319.

[24] F. Ascione, N. Bianco, C. De Stasio, G.M. Mauro, G.P. Vanoli, CASA, cost-optimal analysis by multi-objective optimisation and artificial neural networks: A new framework for the robust assessment of cost-optimal energy retrofit, feasible for any building, Energy Build. 146 (2017) 200-219.

[25] F. Ascione, N. Bianco, R.F. De Masi, G.M. Mauro, G.P. Vanoli, Resilience of robust cost-optimal energy retrofit of buildings to global warming: A multi-stage, multi-objective approach, Energy Build. 153 (2017) 150-167.

[26] L. Georges, C. Massart, G. Van Moeseke, A. De Herde, Environmental and economic performance of heating systems for energy-efficient dwellings: Case of passive and low-energy single-family houses, Energy Policy 40 (2012) 452464.

[27] A.J. Marszal, P. Heiselberg, Life cycle cost analysis of a multi-storey residential Net Zero Energy Building in Denmark, Energy 36 (2011) 5600-5609.

[28] C. Carpino, R. Bruno, N. Arcuri, Social housing refurbishment in Mediterranean climate: Cost-optimal analysis towards the n-ZEB target, Energy Build. 174 (2018) 642-656.

[29] S. Chardon, B. Brangeon, E. Bozonnet, C. Inard, R. Montecot, A Multi-Objective Design Tool for the French Detached House Market: Cost and Energy Performance Optimization. In Proceedings of the Proceedings of BS2015: 14th Conference of International Building Performance Simulation Association, Hyderabad, India, Dec. 7-9, 2015.; Hyderadab, India, 2015.
[30] C. Koller, M.J. Talmon-Gros, R. Junge, T. Schuetze, Energy Toolbox-Framework for the Development of a Tool for the Primary Design of Zero Emission Buildings in European and Asian Cities, Sustainability 9 (2017) 2244.

[31] D. Manjarres, L. Mabe, X. Oregi, I. Landa-Torres, Two-Stage Multi-Objective Meta-Heuristics for Environmental and Cost-Optimal Energy Refurbishment at District Level, Sustainability 11 (2019) 1495.

[32] M. Amer, S. Attia, Identification of sustainable criteria for decision-making on roof stacking construction method, Sustain. Cities Soc. 47 (2019) 101456.

[33] S. Attia, Towards regenerative and positive impact architecture: A comparison of two net zero energy buildings, Sustain. Cities Soc. 26 (2016) 393-406.

[34] F. Dieleman, M. Wegener, Compact city and urban sprawl, Built Environ. 30 (2004) 308-323.

[35] Nabielek, K. Urban Densification in the Netherlands: National Spatial Policy and Empirical Research of Recent Developments. In Proceedings of the Global Visions: Risks and Opportunities for the Urban Planet; International Forum on Urbanism [IFoU]: National University of Singapore, 2011.

[36] A. Skovbro, Urban densification: An innovation in sustainable urban policy?; Copenhagen, Denmark, 2001.

[37] R. Ewing, K. Bartholomew, S. Winkelman, J. Walters, D. Chen, Growing Cooler: The Evidence on Urban Development and Climate Change; Urban Land Institute: Washington, D.C, 2008; ISBN 978-0-87420-082-9.

[38] M.G. Riera Pérez, E. Rey, A multi-criteria approach to compare urban renewal scenarios for an existing neighborhood. Case study in Lausanne (Switzerland), Build. Environ. 65 (2013) 58-70.

[39] K. Steemers, Energy and the city: density, buildings and transport, Proc. Energy Build. 35 (2003) (2003) 3-14.

[40] A.-F. Marique, S. Reiter, A simplified framework to assess the feasibility of zero-energy at the neighbourhood/community scale, Energy Build. 82 (2014).

[41] S. Attia, Net Zero Energy Buildings (NZEB): Concepts, Frameworks and Roadmap for Project Analysis and Implementation, Elsevier, 2018, ISBN 9780-12-812461-1.

[42] M. Amer, S. Attia, A Framework for Cost-Optimal Zero-Energy Lightweight Construction.; Atlanta GA, USA, 2019.

[43] S. Attia, L. Beltrán, A. De Herde, J. Hensen, Architect Friendly": A comparison of ten different building performance simulation tools. 2009.

[44] S. Attia, M. Hamdy, W. O’Brien, S. Carlucci, Assessing gaps and needs for integrating building performance optimization tools in net zero energy buildings design, Energy Build. 60 (2013) 110-124.

[45] C. Waibel, T. Wortmann, R. Evins, J. Carmeliet, Building energy optimization: An extensive benchmark of global search algorithms, Energy Build. 187 (2019) $218-240$.

[46] M. Sadeghipour, Roudsari M. Pak, Ladybug: A Parametric Environmental Plugin for Grasshopper to Help Designers Create an EnvironmentallyConscious Design. In Proceedings of the Proceedings of BS2013: 13th Conference of International Building Performance Simulation Association, Chambéry, France, August 26-28; Chambery, France, 2013.

[47] A.-T. Nguyen, S. Reiter, P. Rigo, A review on simulation-based optimization methods applied to building performance analysis, Appl. Energy 113 (2014) 1043-1058.

[48] A. Brandão de Vasconcelos, M.D. Pinheiro, A. Manso, A. Cabaço, A Portuguese approach to define reference buildings for cost-optimal methodologies, Appl. Energy 140 (2015) 316-328.

[49] S.P. Corgnati, E. Fabrizio, M. Filippi, V. Monetti, Reference buildings for cost optimal analysis: Method of definition and application, Appl. Energy 102 (2013) 983-993.

[50] S. Van de Voorde, I. Bertels, I. Wouters, post-war building materials: in housing in brussels 1945-1975, Graphius Group, Gent: Vrije Universiteit Brussel ISBN (2015).

[51] P. Deboosere, Brussels: A city, a region, a place to live. What does geography teach us about the future of Belgium's institutions 2010, Re-Bel e-book 7.

[52] M. Paryski, I. Pankratieva, A Response to Brussels' Unexpected Population Growth in a Context of Existing Urban Fabric, or How to Densify while Keeping High Quality of Life.; Perm, Russia, 2012.

[53] W. Feist, S. Peper, M. Von Oesen, Klimaneutrale PassivhausReihenhaussiedlung Hannover- Kronsberg; CEPHEUS - Cost Efficient Passive Houses as European Standards; Passivhaus Institue: Hannover, Germany, 2001.

[54] C. Dessouroux, R. Bensliman, N. Bernard, S. De Laet, F. Demonty, P. Marissal, J. Surkyn, Note de synthèse BSI. Le logement à Bruxelles: diagnostic et enjeux, Brussels Studies Institute, 2016.

[55] EN ISO 10456 Building materials and products - Hygrothermal properties Tabulated design values and procedures for determining declared and design thermal values.

[56] A. Cacabelos, P. Eguía, L. Febrero, E. Granada, Development of a new multistage building energy model calibration methodology and validation in a public library, Energy Build. 146 (2017) 182-199.

[57] F. Ascione, N. Bianco, O. Böttcher, R. Kaltenbrunner, G.P. Vanoli, Net zeroenergy buildings in Germany: Design, model calibration and lessons learned from a case-study in Berlin, Energy Build. 133 (2016) 688-710.

[58] M. Royapoor, T. Roskilly, Building model calibration using energy and environmental data, Energy Build. 94 (2015) 109-120.

[59] EN 15459 - Energy performance of buildings - Economic evaluation procedure for energy systems in buildings. 
[60] ISO 15686-5:2008 Buildings and constructed assets - Service-life planning Part 5: Life-cycle costing Available online: http://www.iso.org/cms/render/ live/en/sites/isoorg/contents/data/standard/03/98/39843.html (accessed on Apr 23, 2019).

[61] EN 13501-2 Fire classification of construction products and building elements - Part 2: Classification using data from fire resistance tests, excluding ventilation service.

[62] EN ISO 140-1 Acoustics - Measurement of sound insulation in buildings and of building elements - Part 1: Requirements for laboratory test facilities with suppressed flanking transmission.
[63] EN ISO 717-1 Acoustics - Rating of sound insulation in buildings and of building elements - Part 1: Airborne sound insulation.

[64] T. Wortmann, C. Waibel, G. Nannicini, R. Evins, T. Schroepfer, J. Carmeliet, Are Genetic Algorithms Really the Best Choice for Building Energy Optimization? Proceedings of the Proceedings of the Symposium on Simulation for Architecture and Urban Design, Society for Computer Simulation International, San Diego, CA, USA, 2017, 6:1-6:8 